Review Article

\title{
Creep Properties and Constitutive Model of Salt Rock
}

\author{
Qiang Zhang $\mathbb{D}^{1,2}$ Zhanping Song $\mathbb{D},^{1,2}$ Junbao Wang $\mathbb{D}^{1,2}$ Yuwei Zhang $\mathbb{D}^{1,2}$ \\ and Tong Wang $\mathbb{D}^{1,2}$
}

${ }^{1}$ School of Civil Engineering, Xi'an University of Architecture and Technology, Xi'an, Shaanxi 710055, China
${ }^{2}$ Shaanxi Key Laboratory of Geotechnical and Underground Space Engineering, Xi'an 710055, China

Correspondence should be addressed to Zhanping Song; songzhpyt@xauat.edu.cn and Junbao Wang; xajdwangjunbao@163.com

Received 18 August 2020; Revised 7 February 2021; Accepted 23 February 2021; Published 9 March 2021

Academic Editor: Gang Zhou

Copyright (c) 2021 Qiang Zhang et al. This is an open access article distributed under the Creative Commons Attribution License, which permits unrestricted use, distribution, and reproduction in any medium, provided the original work is properly cited.

Due to the advantages of low porosity, low permeability, high ductility, and excellent capacities for creep and damage self-healing, salt rock is internationally considered as the ideal medium for underground storage of energy and disposal of radioactive waste. As one of the most important mechanical properties of salt rock, creep properties are closely related to the long-term operation stability and safety of salt rock underground storage cavern. A comprehensive review on the creep properties and constitutive model of salt rock is put forward in this paper. The opinions and suggestions on the research priority and direction of salt rock's mechanical properties in the future are put forward: (1) permeability variation of salt rock under the coupling effect of temperature and stress; (2) damage mechanism and evolution process under the effect of creep-fatigue interaction and low frequency cyclic loading; (3) microdeformation mechanisms of salt rock and the relationship between microstructure variations and macrocreep behavior during creep process; (4) the establishment of the creep damage constitutive model with simple form, less parameters, easy application, and considering the damage self-healing ability of salt rock simultaneously.

\section{Introduction}

Energy sources such as oil and natural gas are the material basis for the survival and development of the human society and occupy an important strategic position in the national economy. However, the oil reserves in China are pretty little, which largely dependent on imports from abroad, and the energy situation is stringent [1]. Statistics show that China has become the world's largest oil importer since 2018, and the oil dependence on imports has reached $72 \%$ in 2019 . Due to the tension in the current international situation, especially international trade disputes and the political instability in oil exporting countries become increasingly pronounced, the oil supply disruption is inevitable [2]. Once the oil imports are blocked, it will seriously affect the politics, military, economy, and social stability of China [34]. Therefore, China must establish a perfect strategic energy storage system to cope with the influences caused by war, terrorist attacks, earthquakes, and extreme climate on the international energy market and ensure the sustained, rapid, and sound growth of national economy [4].
Compared with other storage media, salt rock has the advantages of low permeability, stable mechanical properties, excellent creep characteristics, and strong damage selfhealing ability. Meanwhile, since salt rock is easy to dissolve in water, the cavity construction by the solution mining method not only can utilize the salt rock comprehensively but also can abase investment costs and reduce environmental pollution [5-7]. Therefore, the salt rock stratum is internationally considered as an ideal medium for underground storage of energy resources and disposal of radioactive waste. According to statistics, western developed countries, such as United States, France, and Germany, have built a large number of salt rock underground storages as national strategic energy reservoirs [8-10]. The salt rock mineral resources in China are affluent and widely distributed. The proven reserves have been exceeded 4,450 billion tons, and the buried depth varies from tens meters to thousand meters, which provides satisfactory geological conditions for the construction of underground storage cavern (USC) [11]. In addition, with the implementation of the national strategic energy reserve plan and the 
constructions of Sichuan-East Gas Transportation Project and the West-East Pipleline Project, the construction of salt rock USC in China has begun. Jintan USC in Jiangsu Province, the first underground salt rock gas storage cavern in China, was put into operation in 2007. And hundreds of USCs have been built in Qianjiang and Yunying salt mine in Hubei Province, Wanzhou salt mine in Chongqing City, and Pingdingshan salt mine in Henan Province [12-14].

As one of the most important mechanical properties of salt rock, creep behavior is a key factor affecting the working life, safety, and stability of salt rock USC [15]. Due to the excellent creep properties, salt rock can able to generate large creep deformation even under a lower deviatoric stress after a long time [16-18]. At present, several scrapped cases of USC caused by the creep behavior of salt rock have been reported. For example, because of the creep properties of salt rock, the baseplate of the Eminence USC in United States rose by $36 \mathrm{~m}$ and the volume decreased by $40 \%$, eventually leading to the failure of the storage. The surface settlement velocity of Kavernen Feldes USC in Germany reached $17 \mathrm{~mm} \cdot \mathrm{a}^{-1}$ during the operation period with the influence range of $3500 \mathrm{~m}$. Although the operation pressure of Tersanne USC in France was maintained at a higher level during operation period, the storage capacity still reduced by $35 \%$ after 9 years. Moreover, most of the salt rock USCs are constructed in the regions with concentrated population and developed economy. Once an accident occurs, it not only affects the security of energy reserve but also causes heavy loss of the people's life and property. Therefore, to ensure the long-term safety and stability of the USC, it is necessary to study the creep properties of salt rock [19-21].

A comprehensive review on the creep properties and constitutive model of salt rock is presented in this paper. First, the influences of stress level, loading path, temperature, and mineral composition on the creep properties of pure or bedded salt rock and its microscopic deformation mechanism are summarised. Second, achievements in the creep constitutive model such as empirical model, component combination model, fractional derivatives model, nonlinear creep model, and damage model considering the damage self-healing ability of salt rock are introduced. Third, the opinions and suggestions on the research priority and direction of salt rock's mechanical properties in the future are put forward.

\section{Creep Properties of Salt Rock}

Laboratory test is the most direct way to investigate the creep properties of rock materials. Compared with in situ measurement, the laboratory test has the advantages of convenient for the long-term observation, save the cost, and carry out repeated tests by excluding secondary factors and controlling the experimental conditions strictly [22-24]. Meanwhile, the laboratory test results not only can reveal the creep behavior of salt rock under different experimental condition but also can provide relevant parameters for the establishment of the creep constitutive model [25-28]. The current studies on the creep properties of salt rock are mainly from the aspects of macrocreep properties and its microscopic deformation mechanism.

2.1. Macrocreep Properties of Salt Rock. At present, uniaxial and triaxial creep tests are mainly used to explore the influences of stress level, loading path, temperature, and mineral composition on the creep properties of pure and bedded salt rock by many scholars [29-31].

2.1.1. Influences of Stress States and Loading Paths on the Creep Properties of Salt Rock. The long-term operation process of salt rock underground gas storage consists of four stages: low-pressure operation stage, gas injection and pressurization stage, high-pressure operation stage, and gas recovery and depressurization stage. The periodical variations of operation pressure of salt rock gas storage put the surrounding rock under different stress states. While the mechanical properties of salt rock under different stress states show some differences [32-34]. Yang et al. [35] investigated the rheological behavior of salt rock under different experimental conditions (as shown in Figure 1).

(1) In Figure 1(a), the influence of axial stress level on the creep behavior of salt rock is mainly investigated. When the other experimental conditions are fixed, dislocation movement of salt rock grains and the energy dissipation process in salt rock both increase with the increasing of axial stress, which can able to promote the production rate of new cracks [36]. Therefore, with increasing of axial stress, the instantaneous deformation, creep strain, and creep rate of salt rock all increase. Especially under uniaxial compression creep condition $\left(\sigma_{3}=0\right)$, this phenomenon is extremely obvious. Generally speaking, the relationship between axial stress and creep rate of salt rock in the steady creep stage (steady creep rate) can be described by power function, exponential function, and hyperbolic sine function. For example, $\mathrm{Xi}$ et al. [37] pointed out that the relationship between axial stress and steady creep rate of salt rock can be described by a power function expressed by the following equation, namely,

$$
\dot{\varepsilon}_{s}=m_{1}\left(\sigma_{1}-\sigma_{3}\right)^{n_{1}},
$$

where $\dot{\varepsilon}_{s}$ is the steady creep rate of salt rock; $\sigma_{1}$ and $\sigma_{3}$ are axial stress and confining pressure, respectively; and $m_{1}$ and $n_{1}$ are material constants, respectively. Rahimi and Hosseini [38] reported that the relationship between axial stress and steady creep rate of salt rock can be expressed by an exponential function represented by the following equation, i.e.,

$$
\dot{\varepsilon}_{s}=m_{2} \exp \left(n_{2} \sigma_{1}\right) \text {, }
$$

where $m_{2}$ and $n_{2}$ are, respectively, material constants.

(2) In Figure 1(b), the influence of confining pressure on the creep properties of salt rock is mainly discussed. 


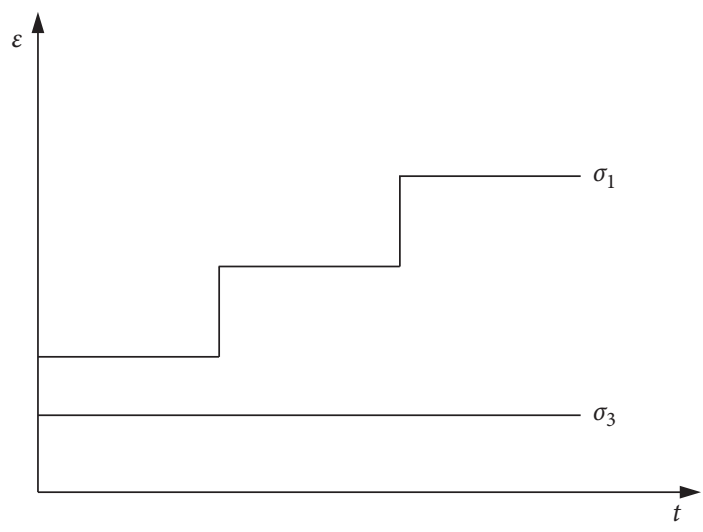

(a)

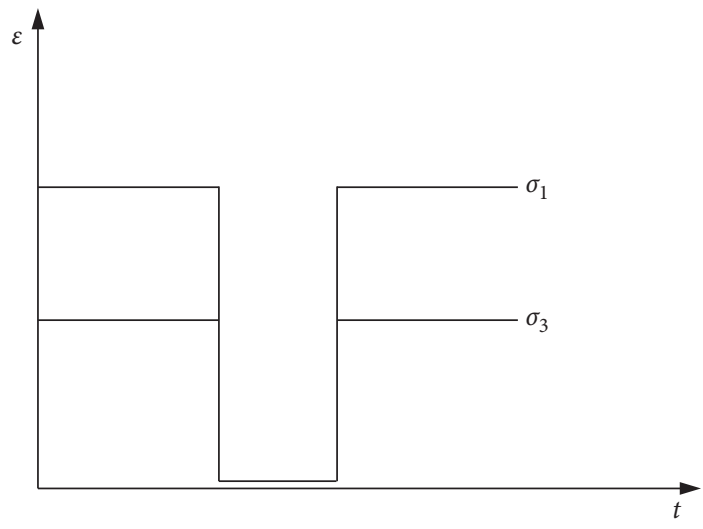

(c)

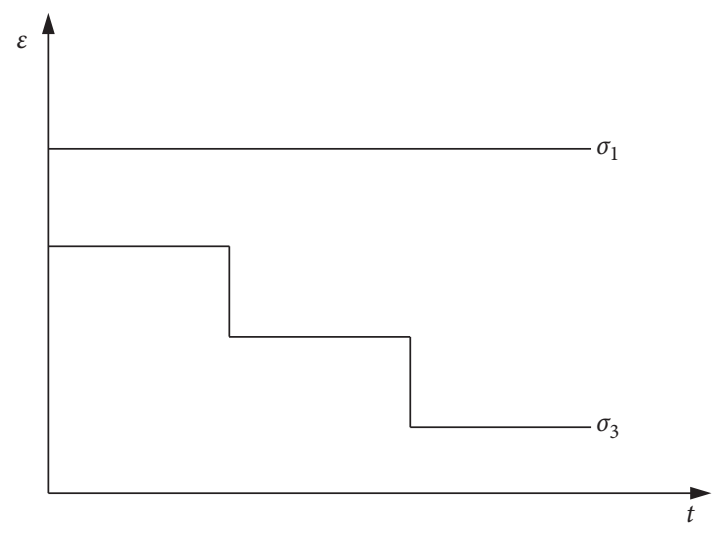

(b)

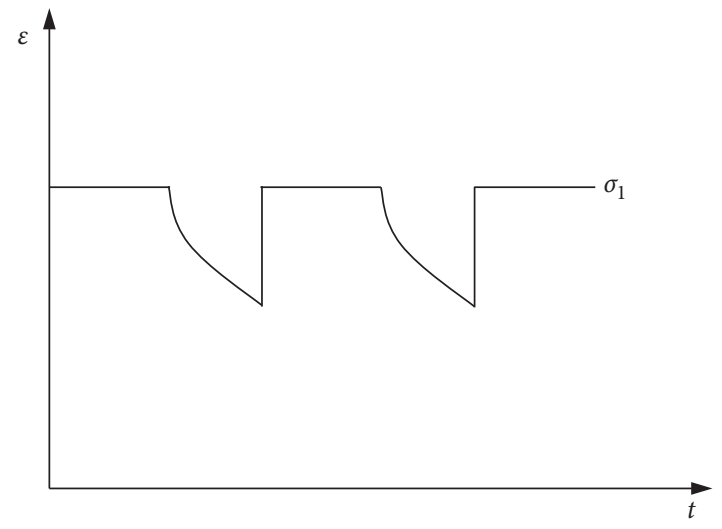

(d)

FiguRE 1: Schematic diagram of loading path: (a) the creep test carried out under multistage loading axial stress (confining pressure was fixed); (b) the creep test carried out under multistage unloading confining pressure (axial stress was fixed); (c) unloaded axial stress and confining pressure to 0 and lasted for a period and then recovered them to the initial state; (d) creep and stress relaxation tests performed alternately [35].

Experimental results obtained by Yang et al. [35] showed that when confining pressure is lower than $3 \mathrm{MPa}$, the steady creep rate of salt rock is sensitive to the variation of confining pressure. At this time, even if there is little change in confining pressure, the steady creep rate of salt rock will alter significantly. When confining pressure exceeds $3 \mathrm{MPa}$, the influence of confining pressure on the steady creep rate of salt rock is obvious weakened. Thereafter, as the further increase in confining pressure, the steady creep rate of salt rock is gradually independent of confining pressure, which can be approximately regarded as a function of axial stress. As a result, an empirical equation reflecting the influence of confining pressure on the creep properties of salt rock can be established:

$$
f\left(\sigma_{3}\right)=m_{3}+n_{3} \exp \left(-\frac{\sigma_{3}}{p_{3}}\right)
$$

where $f\left(\sigma_{3}\right)$ is the influence coefficient of confining pressure on the creep properties of salt rock and $m_{3}$, $n_{3}$, and $p_{3}$ are, respectively, material constants.
In addition, $\mathrm{Du}$ et al. [39] found that when axial stress is the same, the steady creep rate of salt rock decreases with the increase in confining pressure on the whole. However, when confining pressure is lower than $5 \mathrm{MPa}$, the variation of confining pressure has a large effect on the steady creep rate of salt rock; when confining pressure exceeds $5 \mathrm{MPa}$, the influence of confining pressure on its steady creep rate gradually weakened. Wang et al. [40] suggested that when confining pressure does not exceed $4 \mathrm{MPa}$, the changes of confining pressure has a certain impact on the creep behavior of salt rock; however, when confining pressure exceeds $4 \mathrm{MPa}$, the creep behavior of salt rock is independent of confining pressure. The results obtained by $\mathrm{Wu}$ et al. [41] showed that when confining pressure is 5 and $10 \mathrm{MPa}$, the failure pattern of salt rock mainly exhibits shear failure; when confining pressure is 15 and $20 \mathrm{MPa}$, the failure pattern of salt rock presents drum-shaped failure with large deformation (as shown in Figure 2).

All above research results indicate that there is a critical value for the influence of confining pressure 


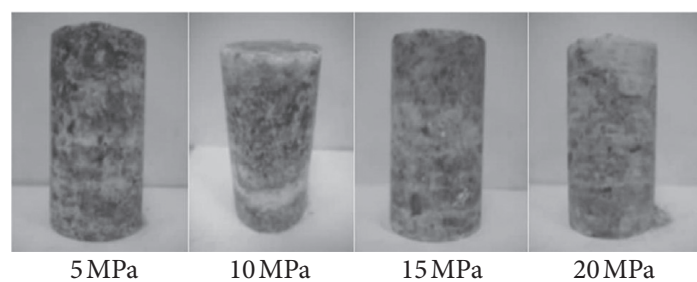

(a)

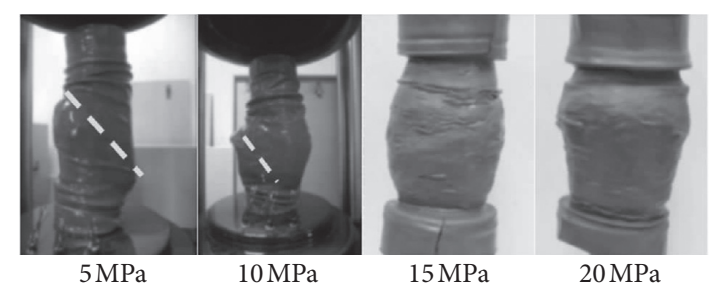

(b)

FIgURE 2: Comparison of salt rock (a) before the creep test and (b) after the creep test [41].

on the creep behavior and failure pattern of salt rock. When confining pressure is lower than the critical value, the creep behavior of salt rock is sensitive to the variation of confining pressure. However, when confining pressure is higher than the critical value, the creep behavior of salt rock becomes independent of confining pressure gradually. This is mainly due to the fact that the existence of confining pressure can effectively hinder the propagation and growth of cracks in salt rock and restrict the development of overall deformation of salt rock. As a result, the steady creep rate of salt rock decreases with the increasing of confining pressure and the creep process is hard to enter the accelerated creep stage under higher confining pressure condition. Meanwhile, the higher the confining pressure, the slower the dislocation movement of salt rock grains and the better the plastic deformation ability of salt rock, which leads to the failure pattern of salt rock changes from shear failure to drum-shaped failure with large deformation.

(3) In Figures 1(c) and 1(d), although the salt rock has underwent different loading paths, the variation law of the total creep strain with time still can be regarded as a complete creep curve. Namely, the impacts of unloading and stress relaxation have little effect on the creep behavior of salt rock. Therefore, the creep behavior of salt rock is only related to the stress state, such as axial stress and confining pressure, but independent of the loading paths.

2.1.2. Influence of Temperature on the Creep Properties of Salt Rock. When the salt rock USC is used as a nuclear waste disposal site, its buried depth is generally greater than 1 $000 \mathrm{~m}$ for security purposes and the ground temperature may exceed $50{ }^{\circ} \mathrm{C}$ [42-44]. Moreover, the decay of radioactive isotopes in nuclear waste can release lots of heat, leading to the rise of surrounding rock temperature. Considering the $5000 a$ as the safety operation time, the surrounding rock temperature of salt rock USC can reach 250 to $400^{\circ} \mathrm{C}$ [45]. High temperature can able to alter the structure of salt rock and lead to the variation in its mechanical properties. Therefore, it is of great significance to study the creep properties of salt rock at different temperatures to ensure the long-term safety and stability of USC [46-48].
In general, the relationship between temperature and creep rate of salt rock can be expressed as follows [49]:

$$
\dot{\varepsilon}=m_{4} \exp \left(-\frac{Q}{R_{0} T}\right)\left(\frac{\sigma}{\sigma^{*}}\right)^{x_{0}}
$$

where $\dot{\varepsilon}$ is the creep rate; $m_{4}$ is the material constant; $x_{0}$ is the stress exponent, with values in the range of 3 to 5 ; $Q$ is the activation energy, which is $54 \mathrm{~kJ} / \mathrm{mol} ; \sigma$ is the deviatoric stress; $\sigma^{*}$ is the reference stress, which is $1 \mathrm{MPa} ; R_{0}$ is the universal gas constant, which is $8.31441 \mathrm{~kJ} /\left(\mathrm{mol} \cdot \mathrm{K}^{-1}\right)$; and $T$ is the temperature.

$\mathrm{Xi}$ et al. [37] found that the relationship between temperature and steady creep rate of salt rock can be expressed by exponential function (as shown in Figure 3). And, the creep failure time of salt rock decreases with the increasing of temperature. When axial stress $\sigma_{1}=19.5 \mathrm{MPa}$, the creep failure time of salt rock is, respectively, 60,53 , and $42 \mathrm{~h}$ when the temperature $T$ is 70,90 , and $110^{\circ} \mathrm{C}$. Gao et al. [50] considered that the relationship between temperature and steady creep rate of salt rock can be described by a linear function. When axial stress $\sigma_{1}=15 \mathrm{MPa}$ and confining pressure $\sigma_{3}=10 \mathrm{MPa}$, the steady creep rate of salt rock at $100^{\circ} \mathrm{C}$ is about 13 times than that at $25^{\circ} \mathrm{C}$. Wan [51] pointed out that high temperature can reduce the strength of salt rock and strengthen its ductility, which will improve its creep properties. When the other conditions remain unchanged, the higher the temperature, the faster the creep rate, the larger the creep strain, and the shorter the creep life [52]. Except for the method of the laboratory test, Li et al. [28] investigated the impact of temperature on the creep properties of salt rock by means of the discrete element model (DEM) method and revealed the damage mechanism of salt rock under different temperature stresses. The catalytic role of temperature on the cracks development in salt rock is further verified by the test results.

The influence mechanism of temperature on the creep properties of salt rock can be explained from the following two aspects. (1) High temperature can enhance the ductility of salt rock to some extent. Namely, with the increase in temperature, the thermal motion of molecules increases and the cohesion between molecules decreases, resulting in the increasing dislocation movement of salt rock grains. (2) Due to the differences in thermal expansion coefficient between different mineral compositions, the uncoordinated thermal expansion deformation of mineral particles at the boundaries may occur. It is impossible for all mineral particles in 


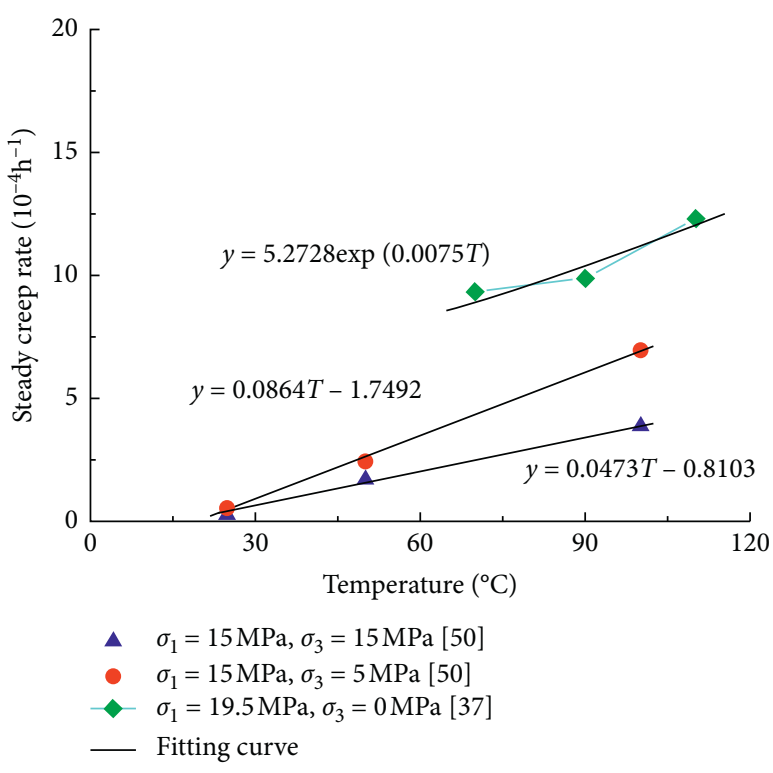

Figure 3: Relationship between temperature and steady creep rate of salt rock $[37,50]$.

salt rock to deform freely according to their own thermal expansion coefficients under the effect of temperature. The mineral particles with large deformation are compressed, while the mineral particles with small deformation are stretched. As a result, the thermal stress caused by temperature is formed in salt rock. The thermal stress always appears at the boundaries between mineral particles and results in the creep failure of salt rock $[53,54]$.

\subsubsection{Influences of Mineral Composition and Microstructure} on the Creep Properties of Salt Rock. The mineral composition is an important factor affecting the creep properties of salt rock. From the view of mineralogical characteristics, except for salt rock grains, there are some associated minerals in salt rock, such as gypsum, thenardite, glauberite, calcite, and quartz, which are usually called impurities [55-57]. Seeing from the microview, the structure of salt rock is presented as a random material polymeride which considers the salt rock grains as a unit. Meanwhile, there are lots of cleavage planes (boundaries) that are easy to split between salt rock grains. And the salt rock grains easily slip along the boundaries under the effect of external stress, which is also the main reason that salt rock has excellent rheological properties [58]. For salt rock with impurity, because the deformation capacity of impurity is weaker than that of pure salt rock, the existence of impurity can effectively restrict the overall deformation capacity of salt rock. Therefore, the higher the purity of salt rock, the better the rheological properties.

Liang et al. [59] compared the creep behavior of glauberite with $70 \% \mathrm{Na}_{2} \mathrm{SO}_{4} \cdot \mathrm{CaSO}_{4}$ content and salt rock with more than $95 \% \mathrm{NaCl}$ content under the same experimental conditions. The results showed that the creep rate of the former is only $3.67 \%$ of that of the latter. Li et al. [52] studied the creep properties of three types of salt rock with different
$\mathrm{NaCl}$ contents $(70.6 \%, 86.6 \%$, and $93.0 \%)$. The results reported that $\mathrm{NaCl}$ content is the internal factors that affect the creep characteristics of salt rock, and the decay creep rate and steady creep rate of salt rock both increase with the increasing of $\mathrm{NaCl}$ content. On the basis of analyzed the creep properties of artificial synthesize salt rock with different $\mathrm{NaCl}$ contents $(20 \%, 40 \%, 60 \%$, and $80 \%), \mathrm{Ma}$ et al. [60] pointed out that as the $\mathrm{NaCl}$ content increases, the creep rate of salt rock increases significantly; and the total creep deformation of artificial synthesize salt rock is contributed by salt rock, while the impurity acts an inhibition role to its deformation ability. The test results provide the further verification for the influence of $\mathrm{NaCl}$ content on the creep behavior of salt rock.

In addition, due to the difference in geological depositional environment, the creep properties of salt rock taken from different regions are also obviously various. Du et al. [39] compared the difference in creep behavior between Yunying salt rock and Jintan salt rock. The results showed that the purity of Yunying salt rock is higher than that of Jintan salt rock, the grain size in the former is relative small, and there are more boundaries between salt rock grains (as shown in Figure 4). The grains in Yunying salt rock are more easier to slip along the boundaries under the action of external loads. Therefore, the creep properties of Yunying salt rock are better than those of Jintan salt rock.

According to the creep test results of Qiaohou salt rock and Changshan salt rock, Qiu et al. [61] found that there are lots of microdefects in Changshan salt rock, and the boundaries between the salt rock grains are highly irregular. Therefore, the dislocation movement of the grains in Changshan salt rock is more obvious than that of Qiaohou salt rock under external loads. The more dislocation movements of the salt rock grains, the more opportunities for them to interact with each other and the more easier to produce dislocation accumulation at boundaries. As a result, obviously the strain hardening phenomenon occurs in Changshan salt rock during the creep process $[62,63]$. However, this phenomenon cannot be found in Qiaohou salt rock due to the difference in microstructure.

2.1.4. Creep Properties of Bedded Salt Rock. The formation of salt rock deposit is closely related to the geological movement, and its occurrence and form vary widely. According to the thickness of deposit, the salt rock deposit can be divided into salt dome and bedded salt deposit. The bedded salt rock deposit refers to the interbedded salt rock composed of salt rock layers with different structure, different components, and different physical-mechanical properties, which usually contains nonsalt materials, such as mudstone, anhydrite, shale, and sandstone, as interlayers [64]. The salt rock domes are scarce in China and many salt rock USCs can only be built in bedded salt deposits. Due to the difference in lithology, the uncoordinated deformation is easily produced between salt rock layers and the interlayers under the external loads. As a result, additional stress may be generated at the interface between the salt rock layer and the interlayers which may cause failure of bedded salt rock. Therefore, 


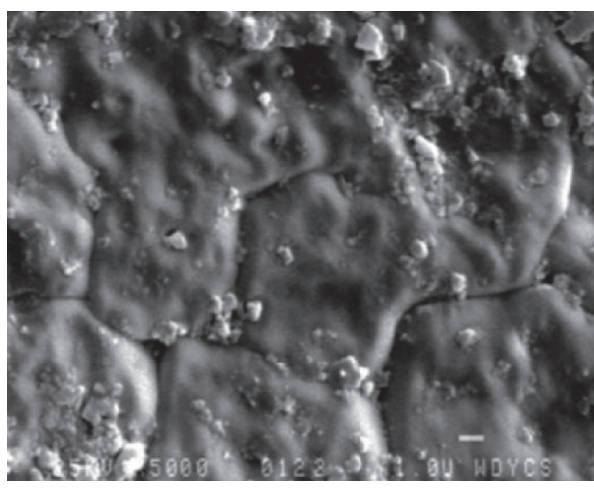

(a)

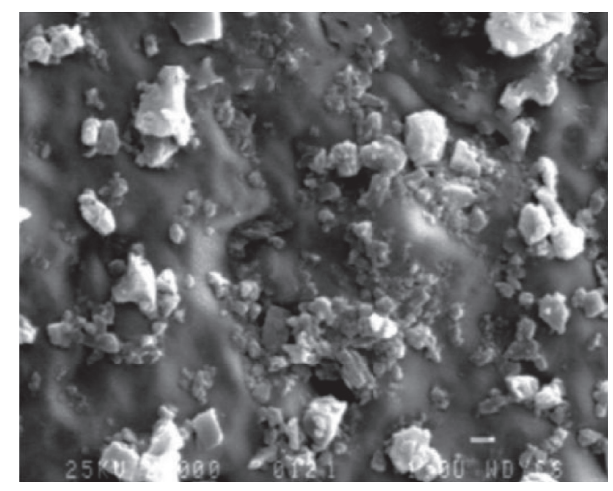

(b)

Figure 4: SEM images of (a) Yunying salt rock and (b) Jintan salt rock [39].

studies on the creep properties of bedded salt rock under different conditions are of great importance for the longterm safety and stability of salt rock USC $[65,66]$.

$\mathrm{Ma}$ et al. [67] compared the difference of creep properties between pure salt rock and bedded salt rock (salt rock with mudstone interlayers) under same experimental condition. And the test results showed that the stress sensitivity and creep properties of pure salt rock are stronger than that of bedded salt rock, which results that the creep strain of the former is larger than that of the latter [68]. Tang et al. [69] showed that the steady creep rate of pure salt rock is about 7 times that of mudstone under the same experimental condition and deduced that the creep deformation of bedded salt rock is mainly contributed by salt rock layer, and the creep deformation capacity of bedded salt rock is between pure salt rock and mudstone. Wang et al. [70] studied the time-dependent deformation of bedded salt rock using numerical experiment approaches and found that the interlayer has obviously inhibition effect on the creep behavior of bedded salt rock. In addition, Xi et al. [37] considered that the lateral strain rate of pure salt rock is about 1.6 to 1.8 times than that of interlayers. It is precisely because the difference in lateral creep rate between pure salt rock and interlayers leads to the salt rock layers outward bulge and the interlayers invaginate during the creep process [71], as shown in Figure 5.

According to theoretical analysis and the long-term creep test on bedded salt rock, Liang et al. [72] found that due to the difference in physical and mechanical properties and uncoordinated deformation between pure salt rock and interlayers, the shear stress will be generated at the interface between two the rocks. With the increase in creep time, the shear stress increases faster and faster. Only when the shear stress exceeds the shear strength of the interface, the creep failure of bedded salt rock occurs. Ma et al. [73] considered that the creep damage of bedded salt rock results jointly from the additional stress arising from the creep deformation difference and stress in the same direction of the effect. Only when this costress exceeds the interlayer tensile strength, an interlayer failure of salt rock happens.

In conclusion, the differences between physical and mechanical properties of salt rock and interlayers are the

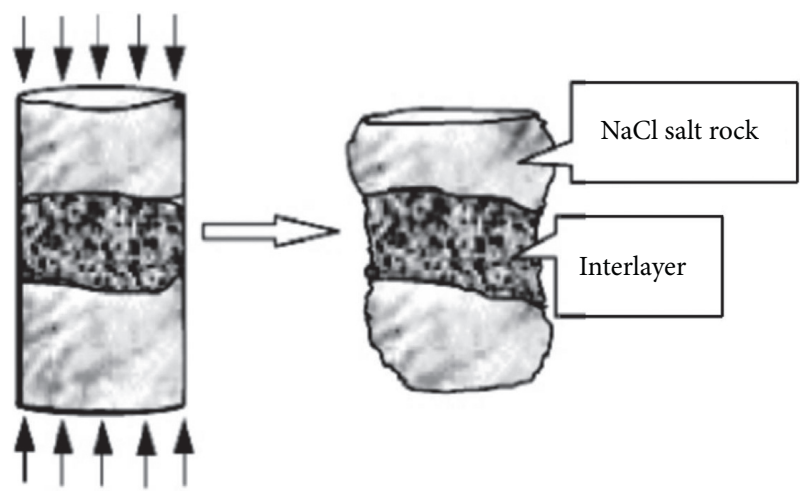

FIGURE 5: Creep failure sketch map of bedded salt rock [71].

major reason that induce the creep failure of bedded salt rock under external loads [74-76]. Namely, the creep deformation of salt rock and interlayers is uncoordinated under the same conditions due to differences in deformation abilities. In this condition, additional stress, such as shear stress and tensile stress, may occur at the interfaces between salt rock and interlayers. The creep failure of bedded salt rocks happens when the additional stress exceeds the strength of the interfaces.

\subsection{Microscopic Creep Deformation Mechanism of Salt Rock.} Salt rock is a typical crystalline material, and its creep behavior under the effect of stress is the macroscopic reflection of internal microstructural changes. Namely, under the action of external conditions, such as stress and temperature, the microstructure of the salt rock will be inevitably changed significantly, which can lead to the variations in its mechanical properties [77, 78].

The main purpose of micromechanics studies on salt rock during creep process is to distinguish its creep deformation mechanism rock under different conditions [79]. The earliest studies on microcreep deformation mechanism of salt rock can be tracked to the 1970s. Ashby [80] first proposed the microdeformation mechanism map (as shown in Figure 6) for metal, ceramic, and alkaline haloid under the conditions of different stresses levels and different 


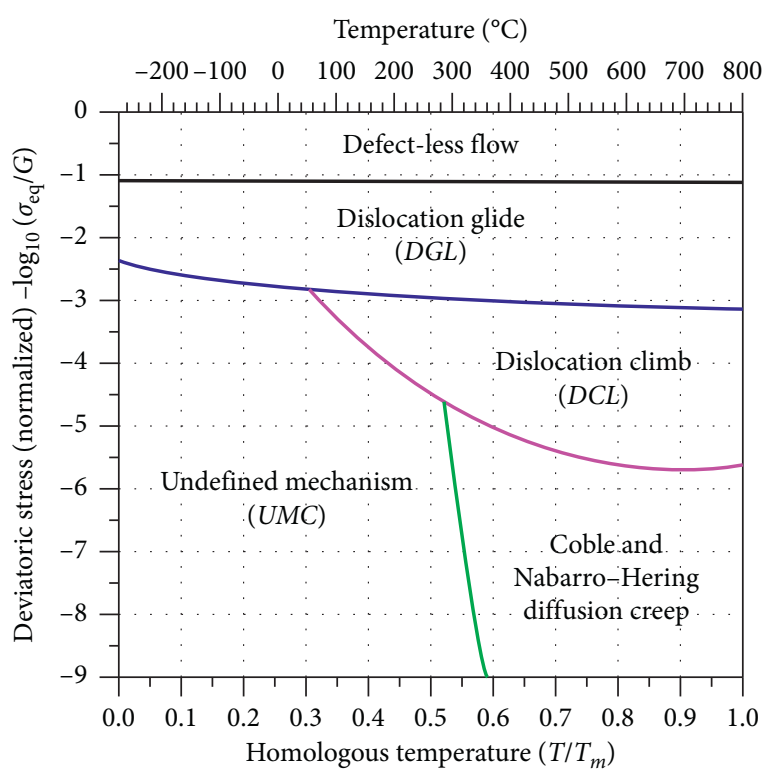

Figure 6: Deformation mechanism map for salt rock. $G$ is the elastic shear modulus of salt, and $\mathrm{T}$ is the melting temperature of salt rock, adopted as $1077 \mathrm{~K}[81,82]$.

temperatures. And then, it was used to describe the creep deformation mechanism of salt rock by Munson and Dawson [81]. As shown in Figure 6, the creep process of salt rock is mainly governed by dislocation mechanisms (dislocation slip and dislocation climb) or diffusion processes depending on the temperature and the deviatoric stress. Note that the undefined mechanism in Figure 6 is distinct from the dislocation and diffusion mechanisms, but it also contributes to the creep process of salt rock. However, the association of these mechanisms to micromechanical models is not at all clear [82].

Actually, the creep deformation process of salt rock is very complicated, which is controlled by many factors such as stress and temperature. This process may be individually controlled by one mechanism under some specific conditions; however, it is controlled by several mechanisms in parallel in the vast majority of cases. Munson et al. [83] summarised the microcreep deformation mechanisms of salt rock under different conditions. The results showed that the creep deformation of salt rock is mainly controlled by the dislocation slip mechanism under high-stress conditions, while it is controlled by dislocation climb mechanism under low stress and high temperature conditions. Horseman and McEwen [84] found that high-stress conditions can able to cause the transgranular creep fracture of salt rock grains and form hollows and cracks in salt rock. With the increase in creep time, these hollows and cracks converge and expand gradually. Meanwhile, high temperature can further promote the formation and development of hollows and cracks in salt rock. Moreover, salt rock grain structure can be dissolved when water molecules enter into salt rock, and a water film can be formed nearby the grain structure, which can promote the release of elastic energy stored in salt rock and accelerate the creep development process of salt rock.
Carter et al. [85] considered that the creep deformation of salt rock is controlled by dislocation mechanism in the temperature ranges from 20 to $200^{\circ} \mathrm{C}$. And the dominant mechanism of creep deformation gradually transits from dislocation slip to dislocation climb with the increasing of temperature. The research results by Spiers and Carter [86] showed that the generation of subgrains is the main development way of the microstructure of salt rock under low stress and appropriate temperature range $\left(100\right.$ to $\left.200^{\circ} \mathrm{C}\right)$ conditions. At this time, the self-healing effect of salt rock occupies the dominant role during the creep process. Muhammad et al. [87] found that when temperature $T=125^{\circ} \mathrm{C}$, the dislocation climb creep mechanism of salt rock is closely related to the confining pressure, while the variation of confining pressure has little effect on the dislocation slip creep mechanism. Based on the creep experimental results of salt rock, Carter and Hansen [88] studied the relationship between the subgrain size and stress and pointed out that for salt rock with bigger grain size, the plastic flow of salt rock exhibits the slip between grain boundaries. However, for salt rock with smaller grain size, the self-healing characteristic realized by the migration of subgrain boundaries occupies the dominant role. Poirier [89] found that the subgrain size variation of salt rock during creep process is only related to axial stress level, and it is independent with pressure confining. The relationship between subgrain size of salt rock and axial stress axial level can be described as follows:

$$
d_{0}=m_{5} \sigma_{1}^{-n_{5}}
$$

where $d_{0}$ is the subgrain size of salt rock; $m_{5}$ and $n_{5}$ are, respectively, material constants, and the value range of $n_{5}$ is from 0.5 to 1.5 .

With the continuous development of science and technology, the observation methods of microstructure variation during rock creep process are also becoming increasingly abundant $[90,91]$. Schenk et al. [92] and Desbois et al. [93], respectively, observed the fluid distribution conditions in grain boundary of fine grain salt rock after creep deformation under the effect of low deviatoric stress by using the cryo-scanning electron microscope (Cryo-SEM) technology and the plasma cutting technology. Ding et al. [94] contrasted the microstructure changes of dry and wet synthetic salt rock by using the optical microscope and found that the creep deformation of dry synthetic salt rock is controlled by dislocation slip mechanism under higher stress ( 32.12 and $38.7 \mathrm{MPa}$ ), while it is controlled by dislocation climb mechanism under lower stress $(18.7 \mathrm{MPa})$. For wet synthetic salt rock, the effect of dynamic recrystallization (grain boundary migration) on the creep deformation is increasingly apparent, which indicates that the microcreep deformation mechanism of salt rock will be transformed under the influence of grain boundary water. Yang et al. [95] observed the microstructure variation of salt rock during creep process using the digital image correlation technique (DICT). The results showed that the creep strain of salt rock under external stress is mainly composed of shear deformation and tension deformation between salt rock grains, 
while the tension deformation is the main reason leading to the generation of damage during creep deformation process.

In addition, acoustic emission (AE) signals are closely related to the development of damage and cracks in rocks under external stress [96]. Therefore, monitoring the AE signals of rocks during creep process not only can obtain the change law of AE parameters, such as AE counts and energy, but also can real-time locate the position of damage and restore the damage evolution process of rocks during creep process. According to the location and counts of AE various time periods, the damage evolution process of rocks under different stress levels and at different periods can be simulated accurately and symbolically [97-99].

Wu et al. [100] studied the AE characteristics of salt rock in the decay creep and steady creep stage by the triaxial creep compression test and explored the damage evolution law under different stress ratios by restoring the AE events (as shown in Figure 7). The red dots in Figure 7 represent the positions of $\mathrm{AE}$ events. It can be seen from Figure 7, with the increase in stress ratio, the $\mathrm{AE}$ events in each stage increase gradually, which indicates that the activity levels of $\mathrm{AE}$ during salt rock creep process are closely related to stress ratio. When the stress level is low (with the stress ratio of $40 \%, 50 \%$, and $60 \%$ ), the AE events are relatively small. When stress is high (with the stress ratio of $60 \%$ and $70 \%$ ), the $\mathrm{AE}$ events increase obviously. The phenomenon above can be explained as follows: the AE events in the decay creep stage are mainly caused by the close of the original defects in salt rock, while the AE counts are mainly induced by the generation and development of new cracks in the steady creep stage. With the increases in axial stress, the close rate of the original defects in the decay creep stage and the growth rate of new cracks in the steady creep stage are obviously accelerated. Therefore, the AE events of salt rock increase gradually with the increasing of axial stress level.

From the spatial distribution of $\mathrm{AE}$ events perspective, the AE counts are mainly distributed at the two ends of salt rock at the initial loading stage ( 0 to $5 \mathrm{~min}$ ) due to the influence of end restrain. Thereafter, the AE events gradually gather towards the middle of salt rock, indicating that the new cracks begin to appear in the middle, which is a damage evolution process of salt rock under external stress.

Zeng et al. [101] carried out a one-year uniaxial creep and $\mathrm{AE}$ test for salt rock and studied the AE characteristics change and damage evolution process of salt rock by restoring the AE event points (as shown in Figure 8). According to the axial strain evolution law, the whole creep process of salt rock is divided into decay creep stage (creep time $0<t<200 \mathrm{~d}$ ), steady creep stage (creep time $200 \leq t<320 \mathrm{~d}$ ), and accelerated creep stage (creep time $t \geq 320 \mathrm{~d}$ ). It can be seen from Figure 8, the amounts and distribution position of $\mathrm{AE}$ events of salt rock in various creep time exhibit obvious difference. (1) In the decay creep stage, AE events are distributed in the middle and the two ends of salt rock due to the close of original defects in salt rock and the effect of end restraint, and the AE activity of salt rock is relatively active. (2) In the steady creep stage, the effect of end restraint of the salt rock gradually weakens and the AE events develop toward the middle of salt rock. The interaction between salt rock grains is in dynamic equilibrium state, and the $\mathrm{AE}$ events decrease gradually with the increasing of creep time. (3) In the accelerated creep stage, a lot of cracks are generated in salt rock, the AE events increase rapidly and extend to both ends of salt rock, and finally cover the whole salt rock. Therefore, the damage path of the long-duration creep damage of the salt rock is from the form of "end-central-whole part."

\section{Creep Constitutive Model of Salt Rock}

The constitutive model is the most basic and the most important part in rock rheology mechanics theory, and it is also an imperative link that applies the experimental results into engineering practice. At present, large numbers of constitutive models are proposed by scholars to describe the creep behavior of salt rock based on the creep experimental results $[102,103]$. In general, the creep constitutive models of salt rock established by scholars can be divided into the following categories.

3.1. Empirical Model. The empirical model is a function expression established by the mathematical statistics regression fitting method on the basis of a large number of creep test results of rock. According to the creep experimental results, many scholars put forward lots of empirical models to describe the creep response of salt rock such as Carter et al. [85] established the relationship between steady creep rate of salt rock and deviatoric stress, energy, and temperature. Cristescu [104], Jin and Cristescu [105], and Yang et al. [63], respectively, proposed an empirical model that reflects the creep behavior of salt rock in the decay and steady stage. Xi et al. [106] obtained an empirical model that is use to describe the creep response of bedded salt rock by fitting the creep experimental results. In general, the most commonly used empirical model expressions are exponential function, power function, and logarithmic function, as shown in Table 1.

Research results show that the empirical model can better describe the creep response of salt rock, but there are still some defects [107-109]. First, the form of the empirical model is various, the model parameters are lack of clear physical meaning, and the values are in great difference. Second, due to the restriction of experimental time and conditions, most empirical models can only reflect the creep response of salt rock in the decay and steady stage but cannot describe the creep behavior in the accelerated stage. Therefore, the empirical model is widely used to describe the creep properties of rock in the early studies; however, with the development of rock rheological mechanics theory, the application of this method is less and less $[110,111]$.

3.2. Component Combination Model. The component combination model is one of the most important constitutive models in rock rheology theory. The fundamental principle of this method is that several basic elements are assumed to describe the specific mechanical properties of rock. For example, elastic element ( $\mathrm{H}$ body), plastic element 


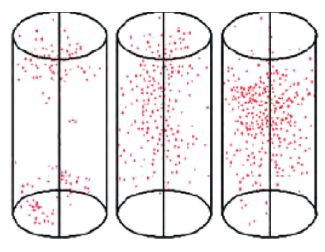

(a)

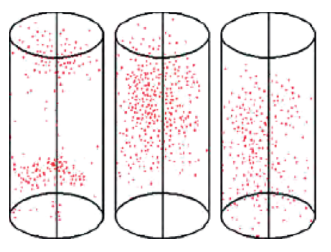

(b)

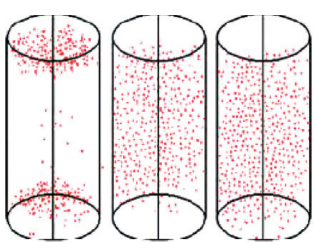

(c)

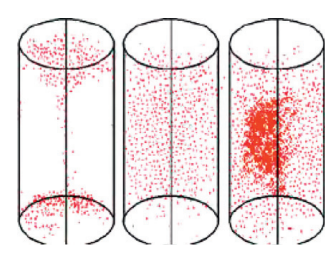

(d)

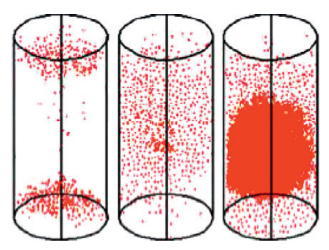

(e)

FIgURE 7: Time-space distribution characteristics of AE under different stress ratios (the time periods from left to right are 0 5 min, 5 30 min, and 30 600 min, respectively): (a) stress ratio of 40\%; (b) stress ratio of 50\%; (c) stress ratio of $60 \%$; (d) stress ratio of $70 \%$; (e) stress ratio of $80 \%$ [100].

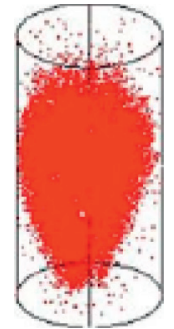

(a)

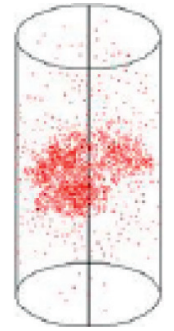

(f)

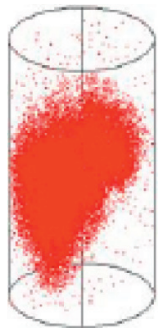

(b)

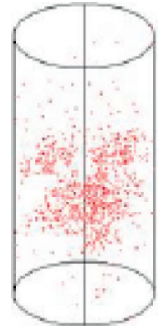

(g)

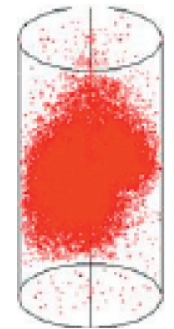

(c)

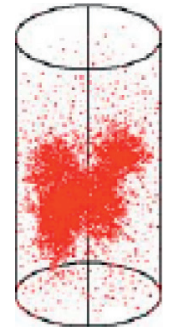

(h)

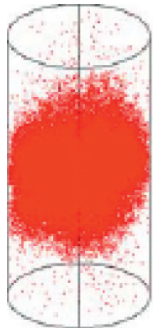

(d)

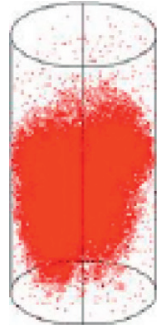

(i)

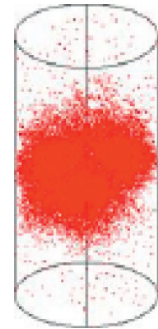

(e)

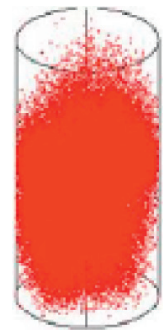

(j)

FIGURE 8: Variation law of AE time-space characteristics of salt rock with creep time: (a) 0 30 d; (b) $60 \sim 66 \mathrm{~d}$; (c) $66 \sim 96 \mathrm{~d}$; (d) $96 \sim 136 \mathrm{~d}$; (e) 136 176 d; (f) 220 260 d; (g) 260 300 d; (h) 260 300 d; (i) 300 330 d; (j) 330 359 d [101].

TABLe 1: Common expressions of the empirical model.

\begin{tabular}{|c|c|c|c|c|}
\hline Model form & Expression & Value of parameters & $\begin{array}{l}\text { Experimental } \\
\text { conditions }\end{array}$ & Ref. \\
\hline \multirow{3}{*}{ Exponential } & $\varepsilon=m_{6}\left(1-e^{-n_{6} t}\right)+p_{6}\left(\sigma / \sigma^{*}\right)^{q_{6}} t$ & $\begin{array}{c}m_{6}=0.01 \\
n_{6}=0.12918 \\
p_{6}=1.108 \times 10^{-8} \\
q_{6}=3\end{array}$ & $\begin{array}{l}\sigma_{1}=4 \text { and } 7 \mathrm{MPa} \\
\text { Time } t>100 \mathrm{~d}\end{array}$ & [59] \\
\hline & & & $\begin{array}{c}\sigma_{1}=14.58 \mathrm{MPa} \\
\text { Failure time }\end{array}$ & \\
\hline & $\varepsilon=m_{7}\left(\sigma / \sigma_{c}\right)\left[p_{7}\left(1-e^{-\left(t / n_{7}\right)}\right)+t e^{-(Q / R T)}\right]+\left(1 / t_{F}-t\right)$ & $\begin{array}{c}m_{7}=6.783 \times 10^{-4} \\
n_{7}=70 \\
p_{7}=19.33\end{array}$ & $\begin{array}{c}t_{\mathrm{F}}=3600 \mathrm{~h} \\
P=8.31 \\
\mathrm{kcal} /(\mathrm{mol} \cdot \mathrm{K}) \\
Q=10096.177 \pm 286 \\
7 \mathrm{kcal} / \mathrm{mol}\end{array}$ & [107] \\
\hline & & $m_{8}=3.2 \times 10^{-6}$ & $\sigma_{1}=10-30 \mathrm{MPa}$ & \\
\hline & & $n_{8}=0.36$ & $\sigma_{3}=0 \sim 15 \mathrm{MPa}$ & {$[50]$} \\
\hline Power & $\varepsilon=m_{8} t^{n_{8}}\left(\sigma_{1}-\sigma_{3}\right)^{p_{8}}$ & $\begin{array}{c}p_{8}=2.2 \\
m_{8}=2.13 \times 10^{-6}\end{array}$ & $\begin{array}{c}\text { Time } t=50 \sim 80 \mathrm{~h} \\
\sigma_{1}=10.3-41.4 \mathrm{MPa}\end{array}$ & \\
\hline & & $\begin{array}{l}n_{8}=0.38 \\
p_{8}=2.25\end{array}$ & $\begin{array}{c}\sigma_{3}=0 \sim 10.3 \mathrm{MPa} \\
\text { Time } t=120 \sim 250 \mathrm{~h}\end{array}$ & [108] \\
\hline Logarithmic & $\varepsilon=m_{9}+n_{9} \lg t+p_{9} t$ & $\begin{array}{c}m_{9}=1.16 \times 10^{-3} n_{9}=1.09 \times 10^{-3} \\
p_{9}=2.5 \times 10^{-7}\end{array}$ & $\begin{array}{c}\sigma_{1}=0.61 \mathrm{MPa} \\
\text { Time } t=1000 \mathrm{~h}\end{array}$ & [109] \\
\hline
\end{tabular}


( $\mathrm{Y}$ body), and viscous element ( $\mathrm{N}$ body) are, respectively, used to reflect the elastic property, plastic property, and viscous property of rock. The component combination model can be established by combining these basic elements in different forms according to the specific mechanical properties of rock, such as in series, in parallel, or in seriesparallel (as shown in Figure 9) [112].

Due to the explicit physical meaning of parameters and the ability to visually represent the complex mechanical properties of rocks, the component combination creep model has been widely used in the field of rock rheological mechanics [113]. At present, lots of component combination models have been established by scholars to reflect the creep response of salt rock. Among them, the Burgers model is one of the most commonly used model (as shown in Figure 10(a)). For example, Zhang et al. [55] found that the Burgers model can be used to describe the creep behavior of glauberite, anhydrite, and argillaceous. Tang et al. [69], Mansouri and Ajalloeian [17], and Wang et al. [114], respectively, described the creep behavior of salt rock under uniaxial compression, triaxial compression, and low frequency cyclic loading (constant axial stress and cyclic confining pressure) using the Burgers model.

In addition, Xu et al. [115] used the Nishihara model to describe the creep behavior of glauberite salt rock under uniaxial compression (as shown in Figure 10(b)). Liang et al. [116] found that the generalized Kelvin model can be used to describe the creep behavior of glauberite salt rock under coupling effect of compression and dissolution (as shown in Figure 10(c)). Liu et al. [117] obtained a five-element creep constitutive model by combining Maxwell body and viscoelastic-plastic body in series to describe the creep behavior of salt rock (as shown in Figure 10(d)). Xi et al. [118] established a constitutive model that can describe the creep response of salt rock with mudstone interlayer by connecting the Nishihara model and Kelvin model in series (as shown in Figure 10(e)). Wang et al. [119] proposed a constitutive model to reflect the creep response of bedded salt rock in the decay and steady stage by combining the Kelvin model and the viscoplastic body in series (as shown in Figure 10(f)).

Figure 11 shows the isochronous stress-strain curves of salt rock. It can be seen that when the axial stress is lower than $14 \mathrm{MPa}$, the isochronous stress-strain curves can be regarded as a straight line that basically overlapped, indicating that the elastic modulus $E$ of salt rock does not change with the increase in stress level and the extension of creep time. When the axial stress is higher than $14 \mathrm{MPa}$, the isochronous stress-strain curves gradually deflect to the strain axis, indicating that the elastic modulus $E$ of salt rock decreases gradually with the increase in stress level and the extension of creep time [120].

As shown above (1) salt rock exhibits obviously nonlinear deformation characteristics during the creep process; the larger the axial stress and the longer the creep time, the more obvious the nonlinear deformation characteristics; (2) when the axial stress is lower than $14 \mathrm{MPa}$, the elastic modulus $E$ of salt rock does not change with the increase in stress level and the extension of creep time. On the contrary, the elastic modulus $E$ decreases gradually with the increase

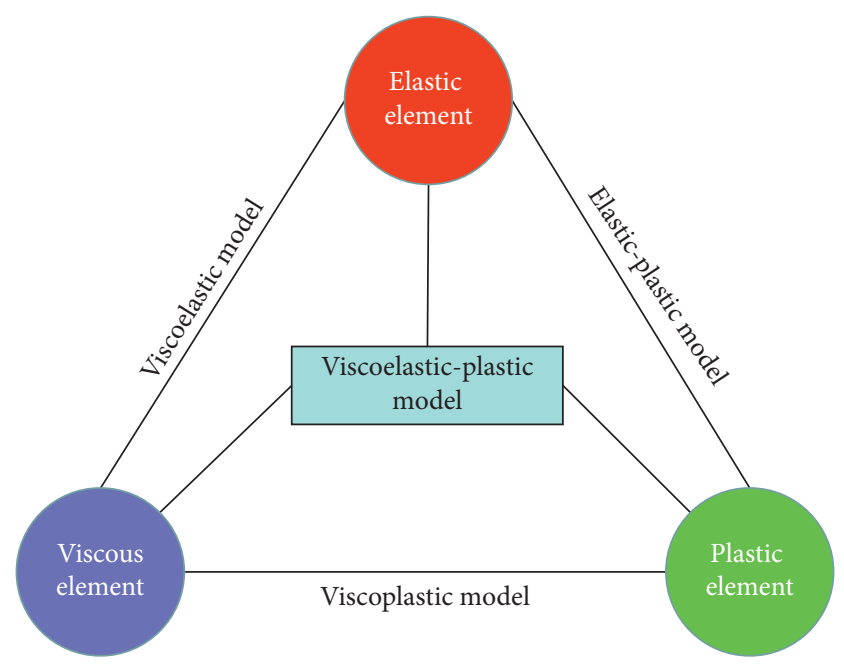

Figure 9: Combination forms of basic elements.

in stress level and the extension of creep time [121]. In addition, Chen et al. [122] pointed out that with the extension of creep time, the variation law of axial creep rate during rock creep process can be divided into the following 3 types: (1) under low-stress level, the axial creep rate of rock gradually decreases and then tends to 0 in a short time; (2) under middle and high-stress levels, the axial creep rate decreases gradually and then quickly tends to an nonzero stable value; and (3) under failure stress level, the axial creep rate gradually decreases to a nonzero stable value and then increases quickly after the stable value is maintained for a period.

According to the constitutive relation of Newton body (Equation (6)), the relationship between viscosity coefficient $\eta$ of rock and creep time also can be divided into 3 types: (1) under low-stress level, with the extension of creep time, the viscosity coefficient $\eta$ of rock increases first and then tends to infinite in a short time; (2) under middle and high-stress levels, with the extension of creep time, viscosity coefficient $\eta$ increases first and then tends to a stable value; and (3) under failure stress level, with the extension of creep time, the viscosity coefficient $\eta$ gradually increases to a stable value and then decreases quickly after the stable value is maintained for a period:

$$
\sigma=\eta \dot{\varepsilon} .
$$

As shown above, the mechanical parameters of rock, such as elastic modulus $E$ and viscosity coefficient $\eta$, continuously change with the variation of stress level and creep time during the creep process. Namely, the elastic modulus $E$ and viscosity coefficient $\eta$ of rock during creep process are closely related to the stress level and creep time. However, the mechanical parameters in traditional component combination models are all assumed as constants. Moreover, rock exhibits obviously nonlinear deformation characteristics during creep process, but the basic elements in the traditional component combination model are all linear. Therefore, the constitutive models, that no matter how these basic elements are combined, cannot describe the whole 


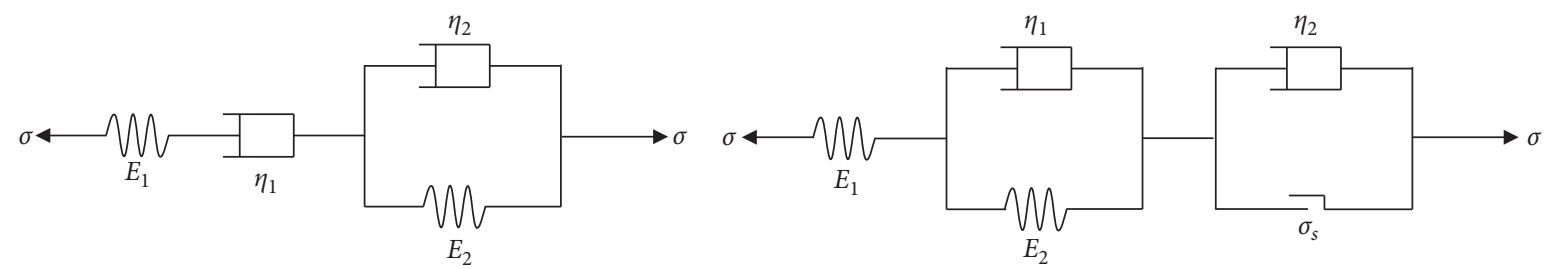

(a)

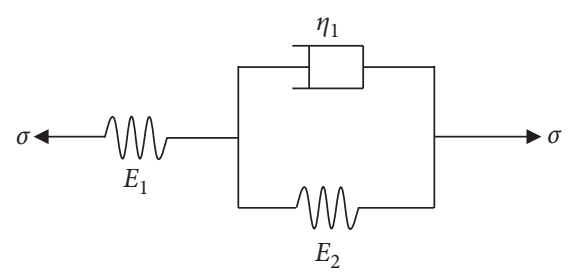

(b)

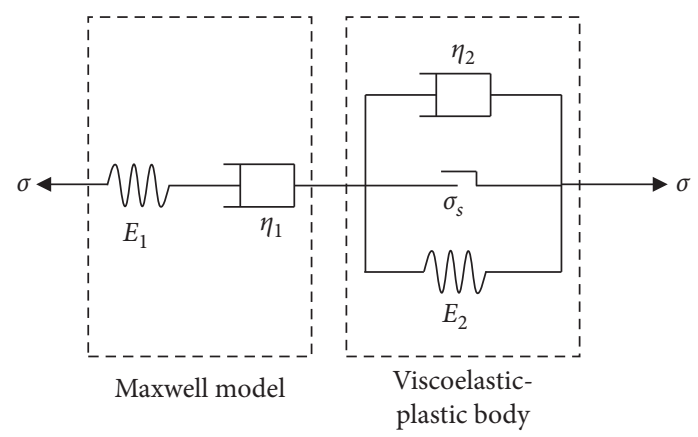

(d)

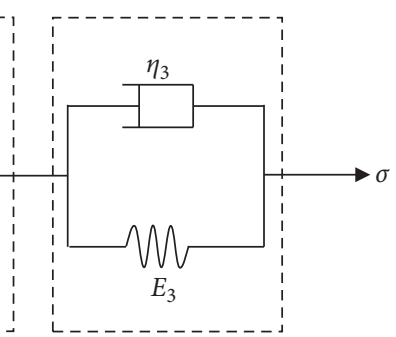

Kelvin model

(e)

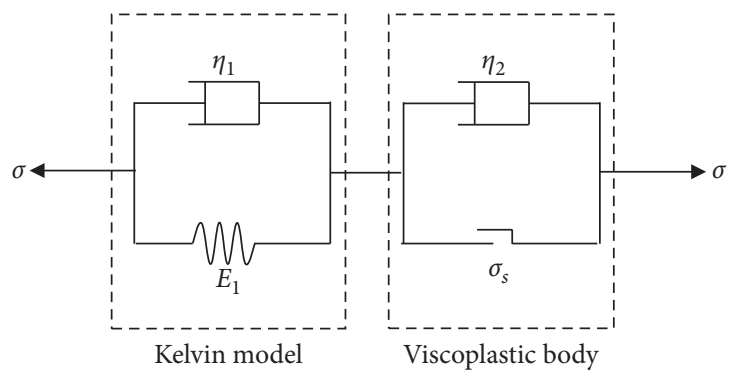

(f)

Figure 10: Schematic diagrams of the component combination model commonly used. (a) Burgers model; (b) Nishihara model; (c) Generalized Kelvin model; (d) Maxwell body and viscoelastic-plastic body in series; (e) Nishihara model and Kelvin model in series; (f) Kelvin model and the viscoplastic body in series.

creep process of rock well, especially cannot reflect the accelerated creep stage [123].

3.3. Fractional Derivatives Creep Constitutive Model. The creep strain state at arbitrary point in rock during creep process is not only related to the stress state of this point at the same instant but also related to the whole stress history before this instant [124]. Fractional calculus is the theory that is used to study the differential and integral of arbitrary order, which is first applied in mathematics field. As an important tool that describes the complicated physical and mechanical behaviors of materials, the definition of fractional derivatives is fully considering the historical reliance of system function development, which has natural advantages in establishing the creep constitutive model of rocks [125]. Therefore, with the development of fractional calculus theory in rock mechanics field, more and more scholars are committed to applying it to the studies of the creep constitutive model of rocks [126].

The basic idea using the fractional calculus theory to establish the creep constitutive model of rocks is described as follows: (1) a nonlinear dashpot (Abel dashpot) is proposed based on the fractional calculus theory and (2) the creep 


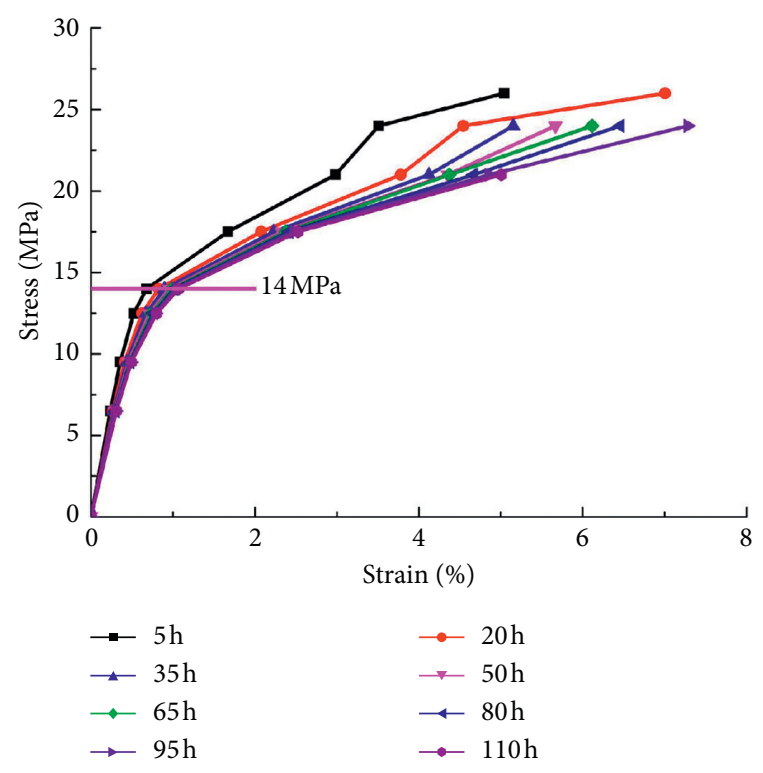

Figure 11: Isochronous stress-strain curves of salt rock [120].

constitutive model of rock can be obtained by replacing the conventional viscous element in existing models with an Abel dashpot or combining the Abel dashpot with other basic elements in different forms [127].

There are many ways to define the fractional calculus; among them, Riemann-Liouville (R-L) is one of the most commonly used method [128], which is described as follows:

Assume $\varphi$ is continuous on $(0,+\infty)$ and integrable on $[0$, $+\infty]$. For $t>0$ and $\operatorname{Re}(a)>0$, the $\beta$-order R-L fractional integral of function $\varphi(t)$ can be described as follows:

$$
\frac{d^{-\beta}[\phi(t)]}{\mathrm{d} t^{-\beta}}=\frac{1}{\Gamma(\beta)} \int_{0}^{t}(t-\xi)^{\beta-1} \phi(\xi) \mathrm{d} \xi,
$$

where $d$ is the differential operator and $\Gamma(\beta)=\int_{0}^{\infty} t^{\beta-1} e^{-t} \mathrm{~d} t$ is the Gamma function.

Assuming $f \in C, t$ and $v>0, m$ is the smallest integer greater than $\beta$, namely, $m-\beta>0$, the $\beta$-order R-L fractional derivative of function $\varphi(t)$ can be expressed as follows:

$$
\frac{d^{\beta}[\phi(t)]}{\mathrm{d} t^{\beta}}=\frac{\mathrm{d}^{m}}{\mathrm{~d} t^{m}}\left\{\frac{d^{-v}[\phi(t)]}{\mathrm{d} t^{-v}}\right\} .
$$

Kiryakova and Al-Saqabi [129] pointed out that the stress-strain relationship of material that between ideal solid and ideal fluid satisfies the following:

$$
\sigma(t)=\eta^{\beta} \frac{d^{\beta}[\varepsilon(t)]}{\mathrm{d} t^{\beta}}, \quad(0 \leq \beta \leq 1),
$$

where $\eta^{\beta}$ is the viscosity coefficient of Abel dashpot and $\beta$ is the derivative order.

Equation (9) is the constitutive equation of Abel dashpot expressed by fractional derivatives, which is called constant coefficient Abel dashpot. The essence of Abel dashpot is an integrated element including elastic element and viscous element.
Keeping the stress fixed, the creep equation of constant coefficient Abel dashpot can be obtained by integrating equation (9), namely,

$$
\varepsilon(t)=\frac{\sigma}{\eta^{\beta}} \frac{t^{\beta}}{\Gamma(1+\beta)} .
$$

Figure 12, respectively, shows schematic diagram of constant coefficient Abel dashpot and its creep characteristic curve. It can be seen from equation (10) and Figure 12, when $\beta=1$ and $\eta^{\beta}=\eta$, equation (10) is transformed into the constitutive equation of ideal fluid (Newton body); when $\beta=0$ and $\eta^{\beta}=E$, equation (10) is converted to the constitutive equation of ideal solid (Hooke body). Thus, the constant coefficient Abel dashpot is an element that can be used to describe stress-strain relationship of materials between Hooke body and Newton body [130]. However, because the value range of derivative order $\beta$ belongs to $[0,1]$, the fractional derivatives creep constitutive model cannot reflect the nonlinear creep characteristics of rocks [131]. Therefore, it is necessary to improve the constant coefficient Abel dashpot and to obtain the constitutive for describing the whole creep process of rocks [132]. At present, the improvement methods of fractional derivative creep constitutive model are mainly through the following three ways.

3.3.1. Adjust the Value Range of Derivative Order $\beta$ in Abel Dashpot. Wu et al. [41] suggested that when the value range of derivative order $\gamma$ belongs to $[1,2]$, the constant coefficient Abel dashpot is converted to a generalized Abel dashpot that can be used to describe the creep behavior of rock between Newton fluid and nonlinear fluid. And then, combining elastic element, constant coefficient Abel dashpot, and generalized Abel dashpot in series, the creep constitutive model of salt rock based on fractional derivatives theory can be obtained (as shown in Figure 13(a)).

Chen et al. [133] considered that when $\gamma>1$, the constant coefficient Abel dashpot is transformed into a super Abel dashpot that can be used to reflect the nonlinear accelerated creep characteristic of rock during the creep process. By replacing the Newton body in the Maxwell model and in viscoplastic body, respectively, with constant coefficient Abel dashpot and super Abel dashpot and then combining these two modified models in series, the creep constitutive model of salt rock based on fractional derivatives theory can be obtained (as shown in Figure 13(b)) [134].

3.3.2. Regard the Derivative Order $\beta$ in Abel Dashpot as a Function of Stress Level or Creep Time. Because the derivative order $\beta$ in constant Abel dashpot is a fixed value and cannot build the effective relations with stress level and creep time, it leads to the parameters of model lack of physical meaning to some extent [135]. Considering this, Wang et al. [136] proposed a variable-order Abel dashpot (as shown in Figure 14(a)) and assumed that the relationship between derivative order $\beta$ and stress level can be described by the exponential function expressed by the following equation: 

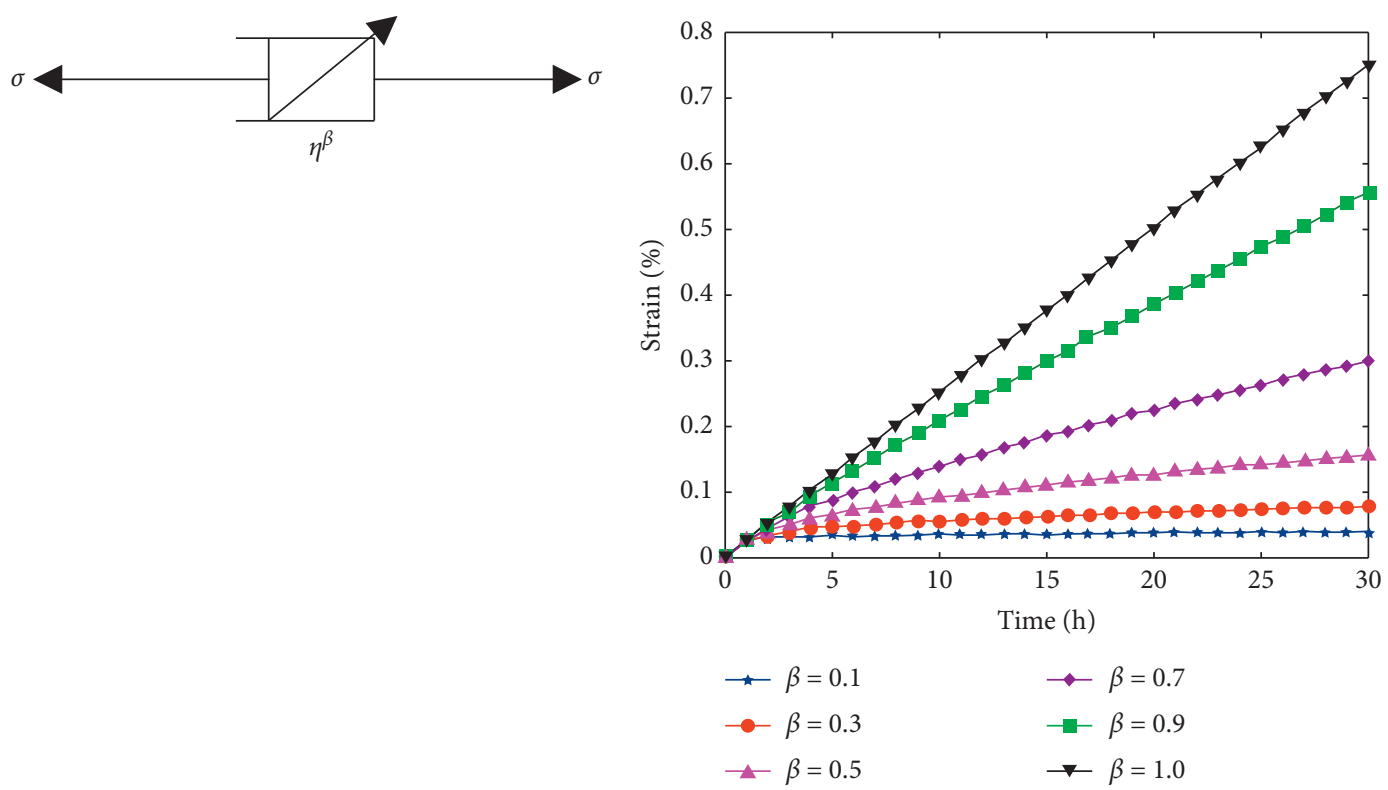

(a)

(b)

Figure 12: Schematic diagram of (a) constant coefficient Abel dashpot and (b) creep characteristic curve [130].

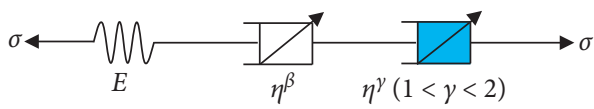

(a)

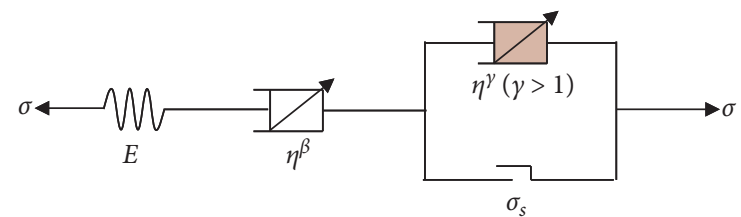

(b)

FIGURE 13: Schematic diagram of the creep model based on fractional derivatives theory by adjusting the value range of derivative order $\beta$ (a) proposed by $\mathrm{Wu}$ et al. [41] $(1<\gamma<2)$ and (b) proposed by Chen et al. [133] $(\gamma>1)$.

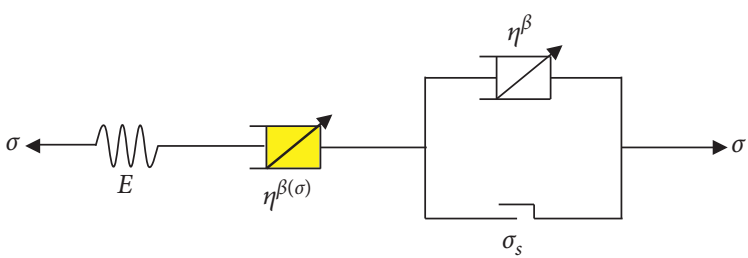

(a)

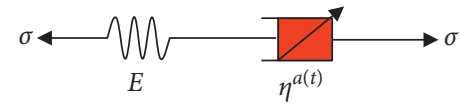

(b)

FIGURE 14: Schematic diagram of the creep model based on fractional derivatives theory (a) proposed by Wang et al. [136] and (b) proposed by $\mathrm{Wu}$ et al. [137].

$$
\beta(\sigma)=m_{10} \exp \left(\frac{\sigma-\sigma_{s}}{\sigma^{*}}\right),
$$

where $\sigma_{\mathrm{s}}$ is the yield stress of salt rock and $m_{10}$ is the material constant.

The Newton body in Bingham body is replaced by the constant coefficient Abel dashpot, and a modified Bingham body can be obtained. By combining elastic body, variableorder Abel dashpot, and the modified Bingham body in series, a creep constitutive model for salt rock based on fractional derivatives theory can be obtained (as shown in Figure 14(a)).
Considering that the mechanical parameters of salt rock gradually decrease with the creep time during creep process, $\mathrm{Wu}$ et al. [137] assumed the derivative order $\beta$ is a function of creep time, i.e., $\beta=\alpha(t), 0 \leq \alpha(t) \leq 1$, and obtained a variable-order Abel dashpot, and the constitutive equation is given as follows:

$$
\sigma(t)=\eta_{t_{i-1}}^{\alpha(t) C} \frac{d^{\alpha(t)} \varepsilon(t)}{\mathrm{d} t^{\alpha(t)}}, \quad 0 \leq \alpha(t) \leq 1, t_{i-1} \leq t \leq t_{i},
$$

where $\alpha(t)$ is the fractional derivative order and is a function of creep time and varies according to Table 2 and $\eta^{\alpha(t)}$ is the corresponding viscosity coefficient. 
TABLE 2: Value $\alpha(t)$ versus creep time [137].

\begin{tabular}{lcccc}
\hline Order & $\alpha_{1}$ & $\alpha_{2}$ & $\ldots$ & $\alpha_{\mathrm{n}}$ \\
\hline Time period & $0 \leq t<t_{1}$ & $t_{1} \leq t<t_{2}$ & $\ldots$ & $t_{\mathrm{n}-1} \leq t<t_{\mathrm{n}}$ \\
\hline
\end{tabular}

An improved Maxwell model for salt rock based on fractional derivatives theory can be established by replacing the viscous body in the Maxwell model with the variableorder Abel dashpot (as shown in Figure 14(b)).

3.3.3. Introduce Damage Variable into Fractional Derivatives Model. The essence of macrocreep deformation process of rock is a process of its internal microcracks evolution and damage accumulation process. Considering that the mechanical parameters of salt rock are no longer a constant during the creep process, especially in the accelerated creep stage, Zhou et al. [130] introduced damage variable into constant coefficient Abel dashpot to describe the degradation of viscosity coefficient of salt rock. At this time, the viscosity coefficient of Abel dashpot can be described as follows:

$$
\eta^{d}=\eta^{\beta}(1-D)
$$

where $\eta^{\mathrm{d}}$ is the viscosity coefficient of variable-order Abel dashpot and $D$ is the damage variable, $0 \leq D \leq 1$.

Assume that the evolution law of salt rock during creep process can be described by an exponential function expressed by the following equation [138], i.e.,

$$
D=1-\exp \left(-m_{11} t\right)
$$

where $m_{11}$ is the material constant.

Combining equations (13) and (14), the expression of viscosity coefficient of variable-order Abel dashpot with damage considered can be obtained. And then, the creep constitutive model of salt rock based on variable-order fractional derivatives and continuum damage mechanics can be obtained by replacing the Newton body in the Nishihara model with variable-order Abel dashpot (as shown in Figure 15).

Based on the study results by Zhou et al. [138], Ding et al. [139], and Liu et al. [140], respectively, the damage variable is redefined from the perspectives of the internal defects in salt rock obey to Weibull random distribution and the $\mathrm{AE}$ characteristics variation law during creep process. And the expressions of damage variable are given as follows:

$$
\begin{aligned}
& D=1-\exp \left(-m_{12} t^{n_{12}}\right), \\
& D=1-\exp \left[-\left(\frac{t}{m_{13}}\right)^{m_{13}}\right],
\end{aligned}
$$

where $m_{12}, m_{13}, n_{12}$, and $n_{13}$ are material constants.

By substituting equations (15) and (16) into equation (13), the expression of viscosity coefficient of variable-order Abel dashpot with damage considered can be obtained. And then, the improved Nishihara model can be established by replacing the Newton body in the Nishihara model with variable-order Abel dashpot. The schematic diagrams of the model are as same as Figure 15.

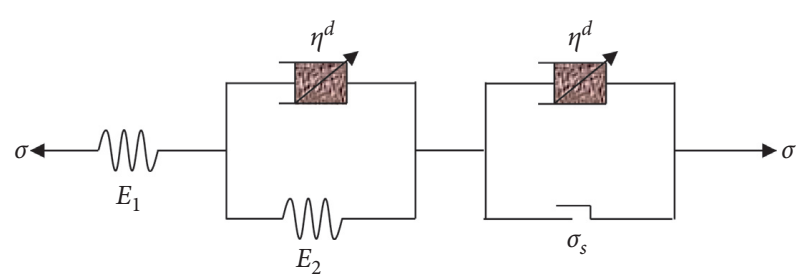

FIgURE 15: Schematic diagram of the improved Nishihara model based on fractional derivatives theory with damage considered.

In the wake of developments in science and technology, nondestructive testing technology has been widely used in many fields due to the advantages of simple to operate, low cost, and little impact on material. Among them, ultrasonic inspection testing is considered as an effective measure to study the damage evolution of rock internal structure $[141,142]$. Based on the creep test results, Ding et al. [143] proposed a damage variable expression from the view of variation of longitudinal wave velocity during creep process of salt rock, namely,

$$
D=1-\frac{1}{1+\varepsilon_{V}} \frac{v_{p}}{v_{0}}
$$

where $\varepsilon_{\mathrm{v}}$ is the volumetric strain and $v_{p}$ and $v_{0}$ are, respectively, the initial wave velocity and longitudinal wave velocity of salt rock.

Introducing the damage variable into elastic element and Newton body in the Kelvin model, an improved Kelvin model with damage considered can be obtained (as shown in Figure 16(a)). The expressions of elastic modulus and viscosity coefficient with damage considered can be described as follows:

$$
\begin{aligned}
& E^{\prime}=E(1-D), \\
& \eta^{\prime}=\eta(1-D),
\end{aligned}
$$

where $E^{\prime}$ and $\eta^{\prime}$ are, respectively, the elastic modulus of elastic body and viscosity coefficient of the viscous body with damage considered.

And then, a three-element creep damage constitutive model for salt rock based on fractional derivatives theory and damage mechanics theory can be obtained by combining the improved Kelvin model and elastic element in series (as shown in Figure 16(b)).

3.4. Nonlinear Creep Constitutive Model. Because the parameters in traditional component combination model are all regarded as a fixed constant, it results in the poor agreement between the theoretical curve and experimental data. Actually, the rheology properties of rock are closely related to time, stress level, stress state, and temperature $[144,145]$. Lv et al. [146] pointed out that the strength, deformation, and rheological parameters of rock have clear time effect, and its rheological parameters, such as elastic modulus $E$, shear modulus $G$, and viscosity coefficient $\eta$, should be a function of time. Sun [22] considered that the creep strain of rock presents a nonlinear increasing tendency with the increasing of stress level, creep time, and stress-strain state, namely, 


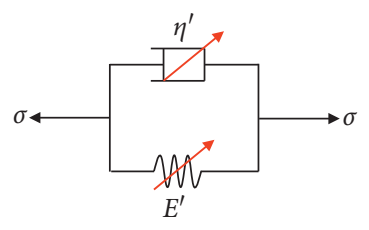

(a)

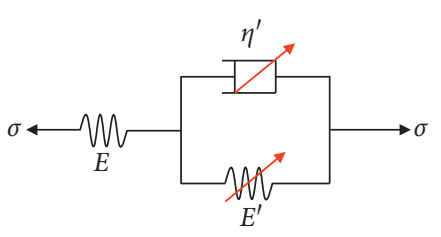

(b)

FIGURE 16: Schematic diagram of the creep damage constitutive model based on fractional derivatives theory and damage mechanics theory: (a) improved Kelvin model; (b) three-element creep damage constitutive model.

$$
\dot{\varepsilon}=\frac{1}{\eta(\sigma, \omega, t)} \sigma
$$

where $\omega$ is the stress-strain state, which can be compression, shear, tension, bend, or other complicated stress states.

However, the traditional component combination models available cannot accurately reflect the nonlinear creep characteristics of salt rock. Therefore, scholars carried out lots of exploratory studies on the nonlinear creep model of salt rock, which can be divided into the following two aspects.

3.4.1. Propose a Nonlinear Element. The basic idea of this method is that the mechanical parameters of rock such as viscosity coefficient $\eta$ are regarded as a variable value that can change with creep time, stress level, or temperature, and then a nonlinear element is constructed. On this basis, a nonlinear creep constitutive model for rock is obtained by replacing the linear element in the traditional component combination model with the nonlinear element or combining the nonlinear element with other elements in different forms.

On the basis of analyzing the factors affecting the nonlinear creep characteristics of salt rock, Wang et al. [147] proposed a nonlinear viscous body and assumed the relationship between the viscosity coefficient and stress level and creep time can be expressed by equation (20). And then, an improved Burgers model that is used to describe the creep behaviors of salt rock in the decay and steady stage can be established by replacing the Newton body in the Burgers model with the proposed nonlinear viscous body (as shown in Figure 17(a)).

$$
\eta(t, \sigma)=\frac{p_{14}}{\sigma^{n_{14}}} \frac{2 \sqrt{t}}{2 \sqrt{t}+m_{14}},
$$

where $\eta(t, \sigma)$ is the viscosity coefficient of nonlinear viscous body and $m_{14}, n_{14}$, and $p_{14}$ are, respectively, material constants.

Based on the research results by Wang et al. [148], Yang et al. [96] proposed a nonlinear viscous body that takes the effect of temperature into consideration, and assuming the relationship between the viscosity coefficient and temperature, stress level and creep time can be described by equation (21). And then, an improved generalized Kelvin model used to describe the creep responses of glauberite salt rock under coupling effect of temperature-solution-stress can be obtained by replacing the Newton body in the modified Kelvin model with the proposed nonlinear viscous body (as shown in Figure 17(b)).

$$
\sigma(T, t, \sigma)=\frac{p_{15}}{q_{15} T^{n_{15}}} \frac{m_{15}+1}{t^{m_{15}+1}},
$$

where $m_{15}, n_{15}, p_{15}$, and $q_{15}$ are, respectively, material constants.

Chen et al. [122] pointed out that there are two kinds of micromechanism in the creep process of rocks by analyzing the results of the rock creep test, namely, hardening mechanism and damage mechanism. On the one hand, the application of external load causes the internal microcracks and micropores of rock to close. Meanwhile, with the extension of the creep time, the position of the rock mineral particles is constantly adjusted, and the microstructure of the rock gradually becomes tight from loose. As a result, the rock porosity decreases and its mechanical properties are hardened. On the other hand, with the extension of the creep time, the microcracks in rock continue to develop and the damage continues to evolve, leading to the gradual deterioration of rock mechanical properties. Therefore, both hardening mechanism and damage mechanism exist at the same time and compete with each other in the creep process of rocks [149]. Based on this idea, Liu et al. [150], respectively, proposed a hardening viscous body and a damage viscous body to reflect the hardening effect and damage effect during the creep process of salt rock. The Newton body in the Burgers model and in viscoplastics body is replaced by the hardening viscous body and damage viscous body. And then, a six-element nonlinear creep model of salt rock can be obtained by combining these two modified models in series (as shown in Figure 17(c)).

For the hardening viscous body, it is assumed that the viscosity coefficient increases gradually with the extension of creep time and it meets the following equation, that is:

$$
\eta_{h}(t)=p_{16} \frac{t+1}{t+1+m_{16}} .
$$

For the damage viscous body, it is assumed that its viscosity coefficient decreases gradually with the extension of time and it meets the following equation, i.e.,

$$
\eta_{d}(t)=p_{17} \frac{\left(1-m_{17} t\right)^{3}}{1+m_{17} t},
$$

where $\eta_{\mathrm{h}}(t)$ and $\eta_{\mathrm{d}}(t)$ are, respectively, the viscosity coefficient of hardening viscous body and damage viscous body; 


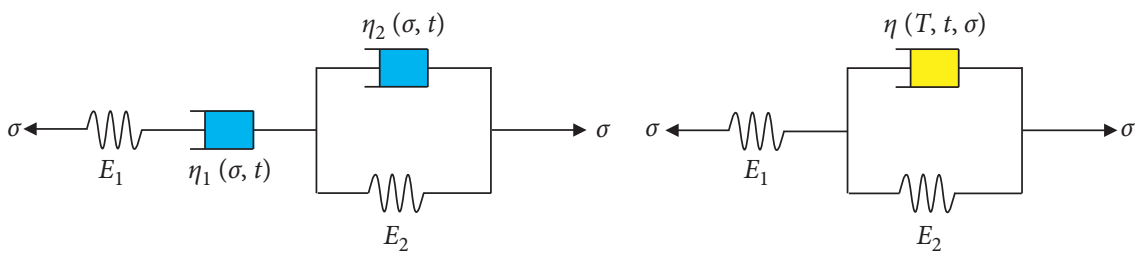

(a)

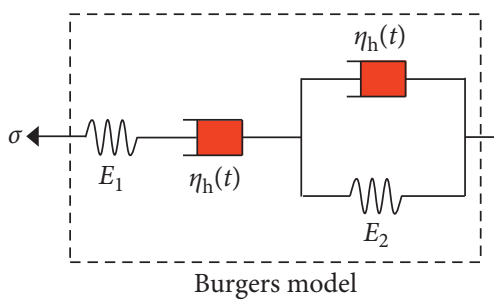

(c) (b)

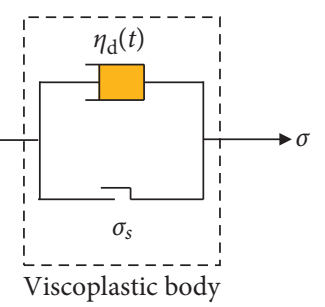

FIGURE 17: Schematic diagram of the nonlinear creep constitutive model (a) improved by Wang et al. [147], (b) improved by Yang et al. [96], and (c) improved by Liu et al. [150].

parameters $m_{16}, m_{17}, p_{16}$, and $p_{17}$ are, respectively, material constants, and $m_{17} t \leq 1$.

The viscosity coefficient expressions of nonlinear elements proposed by other scholars and the corresponding improved model are, respectively, given in Table 3 and Figure 18.

\subsubsection{Add Creep Term or Nonlinear Function with Damage Considered in Existing Model}

(1) Considering the traditional component combination model cannot describe the nonlinear creep behavior of rock well, Hu et al. [156] established an improved Bingham model for salt rock with thermal damage considered by adding a nonlinear function to the Bingham creep model for the decay and steady creep stage and introducing damage for the accelerated creep stage. The schematic diagram of the Bingham model is shown in Figure 19.

The model establishment process is shown as follows: First, the damage variable $D$ and effective stress $\sigma^{\prime}$ with thermal damage are defined as follows:

$D=1-\exp \left\{-\left[\frac{\varepsilon_{1} E-(1-2 v) \sigma_{3}}{\varepsilon_{0} E}\right]\right\}^{m_{25} T^{2}+n_{25} T+p_{25}}$,

$\sigma^{\prime}=\frac{\sigma}{1-D}$

where $v$ is Poisson's ratio; $E$ is the elastic modulus; $m_{25}, n_{25}, p_{25}$, and $\varepsilon_{0}$ are material constants, respectively; and $T$ is the temperature.

Second, in the decay creep stage, a nonlinear function is defined for the Bingham model, namely, $f(t)=$ $1-\exp \left(-m_{26} t\right)$. When $m_{26}$ is an appropriate value, creep time $t$ reaches a certain value, i.e., $f(t)=1$, and then does not change after that.

Third, it is believed that damage does not occur in the decay and steady creep stage, namely, damage only appears in the accelerated creep stage [157]. Therefore, in decay and steady creep stages, there are $D=0$ and $\sigma^{\prime}=\sigma$. At this time, the creep equation can be described as follows:

$$
\varepsilon(t)=\frac{\sigma}{E}+\gamma\left(1-e^{m_{26} t}\right)+\frac{\sigma-\sigma_{s}}{\eta} t
$$

where $\eta$ is the viscosity coefficient

Fourth, when creep process enters into the accelerated creep stage, the effect of damage on rock creep process should be taken into consideration. In this condition, the creep equation is given as follows:

$$
\varepsilon(t)=\frac{\sigma}{E}+\gamma\left(1-e^{m_{26} t}\right)+\frac{\sigma^{\prime}-\sigma_{s}}{\eta} t .
$$

In equation (26), the first term represents the instantaneous creep strain; the second term is used to control the decay and steady creep stage; and the third term is used to describe the accelerated stage with damage considered.

(2) Chen et al. [158] considered that salt rock also can produce damage in decay and steady creep stages. With the increase in stress, the dislocation movement of salt rock grains and the development of microcracks can further promote the propagation of initial damage in salt rock. If the damage value in salt rock is lower than a certain critical value, the creep process exhibits steady creep behavior [159]. With further increase in stress or creep time, the microcracks in salt rock converge and connect with each other, and the damage accumulates gradually, resulting in the appearance of 
TABLE 3: The viscosity coefficient expressions of the nonlinear element and the corresponding modified model.

\begin{tabular}{|c|c|c|c|c|}
\hline Improved model & Expression & Parameters & Ref. & Figure \\
\hline Burgers model & $\eta_{M}(t, \sigma)=p_{18}\left(\sigma / \sigma^{*}\right)^{n_{18}}\left(t / t_{0}\right)^{m_{18}}$ & $\begin{array}{l}m_{18}, n_{18} \text { and } p_{18} \\
t_{0} \text { is the reference time, which is } 1 \mathrm{~h}\end{array}$ & [151] & Figure 18(a) \\
\hline Nishihara model & $\eta_{K}(t)=p_{19} t^{1-m_{19}} \eta_{V}(t)=p_{20}\left(\exp \left(-m_{20} t\right) / 1+m_{20} t\right)$ & $\begin{array}{l}m_{19} \text { and } p_{19} \\
m_{20} \text { and } p_{20}\end{array}$ & [152] & Figure $18(\mathrm{~b})$ \\
\hline Burgers model & $\eta_{M}(t)=p_{21} \exp \left(-m_{21} t\right) \eta_{K}(t)=p_{22} \exp \left(-m_{22} t\right)$ & $\begin{array}{l}m_{21} \text { and } p_{21} \\
m_{22} \text { and } p_{22}\end{array}$ & [153] & Figure $18(\mathrm{c})$ \\
\hline $\begin{array}{l}\text { Nishihara model } \\
\text { Modified Kelvin model }\end{array}$ & $\begin{array}{c}\eta_{V}(t)=p_{23}\left(q_{23} / m_{23} t^{2}-n_{23} t+q_{23}\right) \\
\eta(t)=p_{24}\left(t^{m_{24}} / t+n^{24}\right)\end{array}$ & $\begin{array}{c}m_{23}, n_{23}, p_{23} \text { and } q_{23} \\
m_{24}, n_{24} \text { and } p_{24}\end{array}$ & $\begin{array}{l}{[154]} \\
{[155]}\end{array}$ & $\begin{array}{l}\text { Figure } 18(\mathrm{~d}) \\
\text { Figure } 18(\mathrm{e})\end{array}$ \\
\hline
\end{tabular}

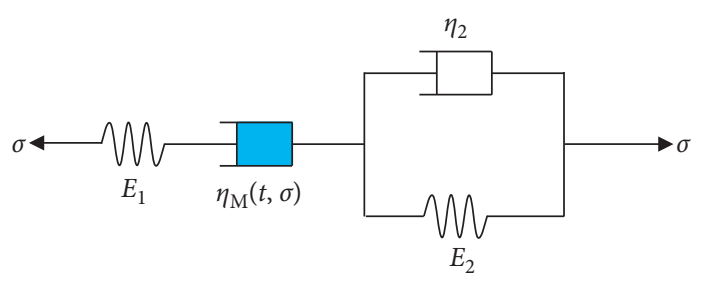

(a)

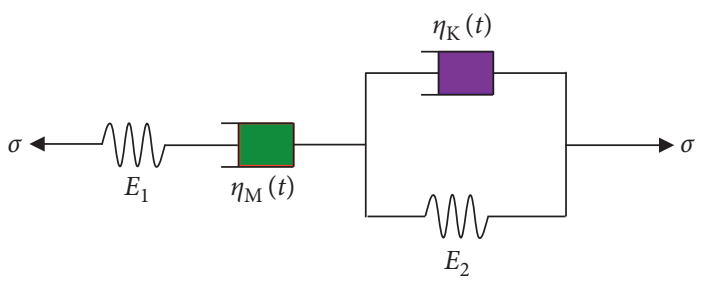

(c)

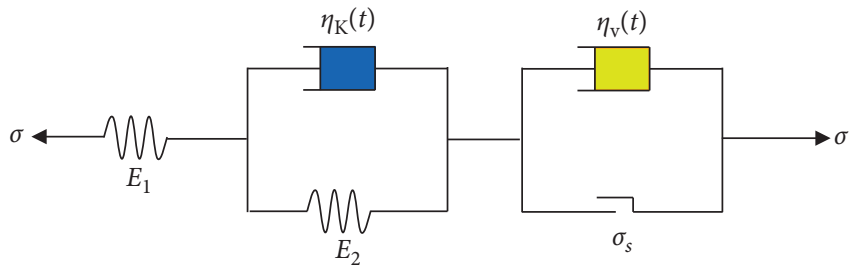

(b)

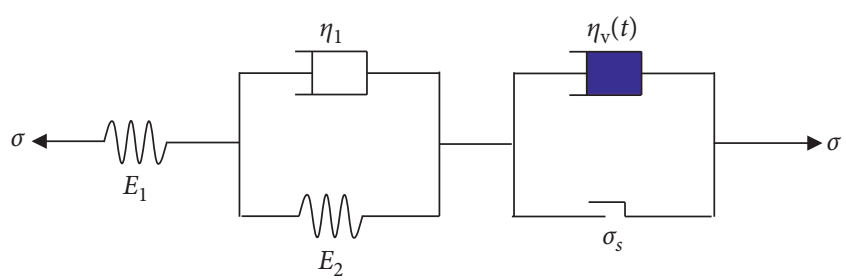

(d)

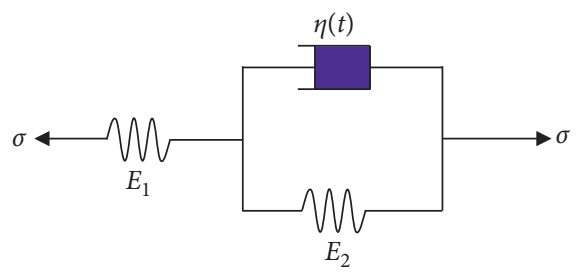

(e)

FIGURE 18: Schematic diagram of the nonlinear creep constitutive model proposed by other scholars (a) improved by Xiong et al. [151], (b) improved by Kang et al. [152], (c) improved by Han et al. [153], (d) improved by He et al. [154], and (e) improved by Liu et al. [155].

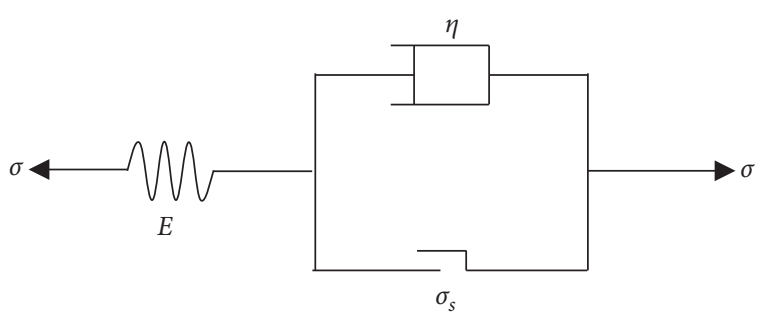

Figure 19: Schematic diagram of the Bingham model.

the accelerated creep stage. Wang [160] considered the damage and took the creep strain produced in the decay stage into consideration, and the Carter model can be expressed as follows:

$$
\varepsilon=\varepsilon_{t}+\varepsilon_{s}+\varepsilon_{d}
$$

where $\varepsilon_{\mathrm{t}}$ is the initial (decay) creep component; $\varepsilon_{\mathrm{s}}$ the steady creep component; and $\varepsilon_{\mathrm{d}}$ is the creep component caused by damage, which, respectively, meet the following:

$$
\begin{aligned}
& \varepsilon_{t}=\frac{\sigma}{m_{28}}\left[1-\exp \left(-\frac{G}{n_{28}} t\right)\right], \\
& \varepsilon_{s}=m_{29} \exp \left(-\frac{Q_{1}}{R T}\right) \sigma^{n_{29}} t, \\
& \varepsilon_{d}=m_{30} \exp \left(-\frac{Q_{2}}{R T}\right)\left(\frac{\sigma}{1-D}\right)^{n_{29}} t,
\end{aligned}
$$


where $m_{28}, m_{29}, m_{30}, n_{28}$, and $n_{29}$ are, respectively, material constants and $G$ is shear deformation modulus.

It is assumed that when the damage variable of salt rock reaches a certain value (which is called "damage accelerating limit"), the development of creep strain enters into the accelerated stage [161]. By extending the Lemaitre-Chaboche damage evolution equation, the following expression can be obtained:

$$
\dot{D}=\left[\frac{\sigma^{e}}{m_{31}(1-D)\left(1-\left\langle D-D_{a}\right\rangle\right)}\right]^{n_{31}},
$$

where $m_{31}$ and $n_{31}$, respectively, are material constants; $\langle x\rangle$ is the switching function; $\sigma^{\mathrm{e}}$ is the damage equivalent stress; $\sigma^{\mathrm{e}}$ and $\langle x\rangle$, respectively, meet the following:

$$
\begin{aligned}
\sigma^{e} & =\sigma\left[\frac{2}{3}\left(1+u_{0}\right)+3\left(1-2 u_{0}\right)\left(\frac{\sigma_{m}}{\sigma}\right)^{2}\right]^{0.5}, \\
\langle x\rangle & = \begin{cases}x, & x \geq 0, \\
0, & x<0,\end{cases}
\end{aligned}
$$

where $u_{0}$ is the instantaneous lateral deformation coefficient and $\sigma_{\mathrm{m}}$ is the spherical stress tensor and meets the following:

$$
\sigma_{m}=\frac{\sigma_{1}+\sigma_{2}+\sigma_{3}}{3}
$$

where $\sigma_{1}, \sigma_{2}$, and $\sigma_{3}$ are the principal stresses in three directions, respectively.

(3) Chen et al. [162] pointed out that the proportion of initial (decay) creep strain in the total creep strain is small that can be neglected. Therefore, it is reasonable only to consider the damage generated in steady and accelerated creep stages in practice engineering. And when the creep strain of salt rock or the damage in salt rock increases to a certain degree, the creep process enters into the accelerated creep stage. At this time, the total creep rate can be expressed as follows:

$$
\dot{\varepsilon}=\dot{\varepsilon}_{s}+\dot{\varepsilon}_{d},
$$

where $\dot{\varepsilon}_{s}$ is the steady creep rate component and $\dot{\varepsilon}_{d}$ is the creep rate component caused by damage.

In the Norton power model, the creep of salt is activated by Mises stress $q$. Therefore, the steady creep rate and its tensor form can be described as follows:

$$
\begin{aligned}
& \dot{\varepsilon}_{\mathrm{cr}}^{s}=m_{32} q^{n_{32}}, \\
& \dot{\varepsilon}_{i j}^{s}=\dot{\varepsilon}_{\mathrm{cr}}^{s} \frac{\partial q}{\partial S_{i j}}=\dot{\varepsilon}_{\mathrm{cr}}^{s} \frac{3}{2} \frac{S_{i j}}{q},
\end{aligned}
$$

$$
q=\sqrt{\frac{3}{2} S_{i j} S_{i j}}
$$

And the creep damage rate caused by Carter damage and its tensor form can be expressed as follows:

$$
\begin{aligned}
& \dot{\varepsilon}_{\mathrm{cr}}^{d}=m_{33}\left(\frac{q}{1-D}\right)^{n_{33}}, \\
& \dot{\varepsilon}_{i j}^{d}=\dot{\varepsilon}_{\mathrm{cr}}^{d} \frac{\partial q}{\partial S_{i j}}=\dot{\varepsilon}_{\mathrm{cr}}^{d} \frac{3}{2} \frac{S_{i j}}{q},
\end{aligned}
$$

where $S_{\mathrm{ij}}$ is the deviatoric stress tensor and $m_{32}, m_{33}$, $n_{32}$, and $n_{33}$ are, respectively, material constants.

Based on the results of Wang [160] and the Kachanov damage evolution, the damage evolution rate of salt can be established, which is as same as equation (29). And then, introducing a function of deviatoric stress and confining pressure into damage equivalent stress, the following equation can be obtained:

$$
\sigma^{e}=q\left[m_{34}+n_{34}\left(\frac{q}{\sigma_{m}}\right)\right]
$$

where $m_{34}$ and $n_{34}$ are, respectively, material constants.

(4) $\mathrm{Ma}$ et al. [163] considered that a complete creep constitutive relationship should cover the whole creep process (namely, decay, steady, and accelerated creep stage) of salt rock, and its damage evolution equation should reflect the accelerated damage trend in the third stage. At this time, the total creep rate can be expressed as follows:

$$
\dot{\varepsilon}=\dot{\varepsilon}_{t}+\dot{\varepsilon}_{s}+\dot{\varepsilon}_{d}
$$

The expressions of steady creep component $\dot{\varepsilon}_{s}$ and creep component $\dot{\varepsilon}_{d}$ are same as equations (33) and (36), and the initial (decay) creep component $\dot{\varepsilon}_{t}$ meets the following:

$$
\dot{\varepsilon}_{t}=\frac{G q}{m_{35}} \exp \left(-\frac{G}{n_{35}} t\right)
$$

where $m_{35}$ and $n_{35}$ are, respectively, material constants.

According to the Kachanov-Rabotnov creep damage theory, the damage evolution equation of salt rock can be described as follows:

$$
\dot{D}=\left[\frac{\sigma^{e}}{m_{36}(1-D)}\right]^{n_{36}} \text {. }
$$

By integrating equation (41) with time $t$ and considering the initial condition $t=0$ and $D=0$, there are 


$$
\begin{aligned}
D & =1-\left[1-(r+1)\left(\frac{\sigma^{e}}{m_{36}}\right)^{r} t\right]^{1 / n_{36}+1}, \\
\sigma^{e} & =q\left\{\frac{2}{3}\left[1+u_{0}+3\left(1-2 u_{0}\right)\left(\frac{\sigma_{m}}{q}\right)^{2}\right]\right\}^{0.5} .
\end{aligned}
$$

3.5. Creep Constitutive Model considering the Damage SelfHealing Ability of Salt Rock. Due to the excellent self-healing ability after damaged, the damage in salt rock can be gradually healed in a proper environment, which result in mechanical properties of salt rock that are restored to some extent [164]. Therefore, scholars proposed the creep constitutive model considering the damage self-healing ability of salt rock [165]. Among them, the most commonly used models are MDCF model and Lux/Hou model.

\subsubsection{Multimechanism Deformation Coupled Fracture} (MDCF) Model. The MDCF model is formulated for processing coupled creep, fracture, and healing of salt rock based on the MD model. In the MDCF model, dislocation creep, shear damage, tensile damage, and damage healing mechanisms are described by individual terms [166], namely,

$$
\dot{\varepsilon}_{i j}^{I}=\frac{\partial \sigma_{\mathrm{eq}}^{c}}{\partial \sigma_{i j}} \dot{\mathcal{E}}_{\mathrm{eq}}^{c}+\frac{\partial \sigma_{\mathrm{eq}}^{\mathrm{d} s}}{\partial \sigma_{i j}} \dot{\varepsilon}_{e q}^{d s}+\frac{\partial \sigma_{\mathrm{eq}}^{\mathrm{d} t}}{\partial \sigma_{i j}} \dot{\varepsilon}_{\mathrm{eq}}^{\mathrm{d} t}+\frac{\partial \sigma_{\mathrm{eq}}^{h}}{\partial \sigma_{i j}} \dot{\varepsilon}_{\mathrm{eq}}^{h},
$$

where the superscripts $c$, ds, dt, and $h$, respectively, represent the terms of coupled creep, shear damage, tensile damage, and damage healing, $\dot{\varepsilon}_{\text {eq }}$ and $\sigma_{\text {eq }}$ represent the equivalent strain rate and the power-conjugate stress measure corresponding to individual mechanism, and $\sigma_{\text {eq }}^{c}, \sigma_{\text {eq }}^{\mathrm{d} s}, \sigma_{\text {eq }}^{\mathrm{d} t}$, and $\sigma_{\text {eq }}^{h}$ are given by

$$
\begin{aligned}
& \sigma_{\text {eq }}^{c}=\left|\sigma_{1}-\sigma_{3}\right|, \\
& \sigma_{\text {eq }}^{\mathrm{d} s}=m_{s}\left(\frac{t_{0}}{t_{f}}\right)^{1 / n_{s}}\left[\ln \left(\frac{1+z}{\omega_{f}}\right)\right]^{-\left(1 / n_{s} a_{1}\right)}, \\
& \sigma_{\text {eq }}^{\mathrm{d} t}=z^{1 / n_{t}}\left[\frac{\sigma_{\text {eq }}^{\mathrm{d} s} H\left(\sigma_{\text {eq }}^{\mathrm{d} s}\right)}{m_{t}}\right]^{-\left(n_{s} / n_{t}\right)}, \\
& \sigma_{\text {eq }}^{h}=\sigma_{b}+\frac{\tau \mu}{t_{h}} \ln \left(\frac{\omega_{h}}{\omega_{0}}\right),
\end{aligned}
$$

with

$$
z=\left[\frac{\sigma_{\mathrm{eq}}^{\mathrm{d} t} H\left(\sigma_{\mathrm{eq}}^{\mathrm{d} t}\right)}{m_{t}}\right]^{n_{t}}\left[\frac{m_{s}}{\sigma_{\mathrm{eq}}^{\mathrm{d} s} H\left(\sigma_{\mathrm{eq}}^{\mathrm{d} s}\right)}\right]^{n_{s}},
$$

where $a_{1}, m_{\mathrm{s}}, m_{\mathrm{t}}, n_{\mathrm{s}}$, and $n_{\mathrm{t}}$ are material constants; $t_{\mathrm{f}}$ and $\omega_{\mathrm{f}}$ are, respectively, time-to-rupture and the critical value of damage variable at creep rupture; $t_{0}$ is a reference time; $t_{\mathrm{h}}$ is the healing time; $\omega_{0}$ is the value of damage variable at the pristine state; $\sigma_{1}$ and $\sigma_{3}$ are maximum and minimum principal stress; $H()$ is the Heaviside function with its argument in parentheses; $\tau$ is the characteristic time for damage healing; $u$ is the shear modulus; $\sigma_{\mathrm{b}}$ is the stress boundary for damage and healing, and $\sigma_{\mathrm{b}}$ and $\tau$, respectively, meet the following:

$$
\begin{aligned}
\sigma_{b} & =a_{3}\left|\frac{\sigma_{1}-\sigma_{3}}{f_{p} a_{2} a_{3}}\right|^{1 / a_{4}}, \\
\tau & = \begin{cases}\tau_{0} \exp \left(a_{5} \varepsilon_{v}\right)+\tau_{1}, & \varepsilon_{v}<0, \\
\tau_{0}+\tau_{1}, & \varepsilon_{v} \geq 0,\end{cases}
\end{aligned}
$$

where $a_{2}, a_{3}, a_{4}$, and $a_{5}$ are material constants; $\tau_{0}$ and $\tau_{1}$ are characteristic time constants; $\varepsilon_{\mathrm{v}}$ is the volumetric strain; and $f_{\mathrm{p}}$ is a particle function that models the effect of clay particles on the damage process, which is given by the following:

$$
f_{p}=\left|1-\frac{a_{6} \rho}{a_{4}}\right| a_{4} \operatorname{sgn}\left(1-\frac{a_{6} \rho}{a_{4}}\right),
$$

where $a_{6}$ is the material constant and $\rho$ is the volume of impurity.

The total creep strain rate is controlled by dislocation glide mechanism $\dot{\varepsilon}_{\mathrm{DG}}$, dislocation climb mechanism $\dot{\varepsilon}_{\mathrm{DC}}$, and undefined mechanism $\dot{\varepsilon}_{\mathrm{UM}}$, which are described as follows [82]:

$$
\dot{\varepsilon}_{s}=\dot{\varepsilon}_{\mathrm{DG}}+\dot{\varepsilon}_{\mathrm{DC}}+\dot{\varepsilon}_{\mathrm{UM}}
$$

In equation (48),

$$
\begin{aligned}
\dot{\varepsilon}_{\mathrm{DG}}= & H\left(\frac{\sigma_{\mathrm{eq}}^{c}}{1-D}-\sigma_{0}\right)\left[B_{1} \exp \left(\frac{-Q_{1}}{R T}\right)+B_{2} \exp \left(\frac{-Q_{2}}{R T}\right)\right] \\
& \cdot \sinh \left[\frac{q}{u}\left(\frac{\sigma_{\mathrm{eq}}^{c}}{1-D}-\sigma_{0}\right)\right], \\
\dot{\varepsilon}_{\mathrm{DC}}= & A_{1} \exp \left(-\frac{Q_{1}}{R T}\right)\left[\frac{\sigma_{\mathrm{eq}}^{c}}{u(1-D)}\right]^{n_{1}}, \\
\dot{\varepsilon}_{\mathrm{DG}}= & A_{2} \exp \left(-\frac{Q_{2}}{R T}\right)\left[\frac{\sigma_{\mathrm{eq}}^{c}}{u(1-D)}\right]^{n_{2}},
\end{aligned}
$$

where $A_{1}, A_{2}, B_{1}$, and $B_{2}$ are material constants; $Q_{1}$ and $Q_{2}$ are activation energies; $n_{1}$ and $n_{2}$ are stress exponents; $T$ is the absolute temperature; $R$ is the universal gas constant; $\sigma_{0}$ is the stress limit of the dislocation slip mechanism; and $D$ is the isotropic damage factor. 
The equivalent strain rate is given by the following:

$$
\begin{aligned}
& \dot{\varepsilon}=F \dot{\varepsilon}_{s}, \\
& F= \begin{cases}\exp \left\{+\Delta\left[1-\left(\frac{\xi}{\varepsilon_{t}^{*}}\right)\right]^{2}\right\}, & \xi<\varepsilon_{t}^{*}, \\
1, & \xi=\varepsilon_{t}^{*}, \\
\exp \left\{-\delta\left[1-\left(\frac{\xi}{\varepsilon_{t}^{*}}\right)\right]^{2}\right\}, & \xi>\varepsilon_{t}^{*},\end{cases}
\end{aligned}
$$

where $\Delta$ and $\delta$ are the hardening and recovery parameters, respectively; $\varepsilon_{t}^{*}$ is the transient strain limit; and $\zeta$ is an internal isotropic hardening variable, which meet the following:

$$
\begin{aligned}
& \Delta=A_{3}+B_{3} \log \left[\frac{\sigma_{\mathrm{eq}}^{c}}{u(1-D)}\right], \\
& \delta=A_{4}+B_{4}\left[\frac{\sigma_{\mathrm{eq}}^{c}}{u(1-D)}\right], \\
& \varepsilon_{t}^{*}=a_{7} \exp \left(a_{8} T\right)\left(\frac{\sigma_{\mathrm{eq}}}{u}\right)^{a_{9}}, \\
& \zeta=(F-1) \dot{\varepsilon}_{s}
\end{aligned}
$$

where $A_{3}, A_{4}, B_{3}, B_{4}, a_{7}, a_{8}$, and $a_{9}$ are material constants.

The creep rate caused by shear damage and tensile damage can expressed as follows:

$$
\dot{\varepsilon}_{\text {eq }}^{D i}=F^{D i} \dot{\varepsilon}_{s}^{D i}
$$

where the superscripts $D i(i=s$, and $t)$ represent shear stress component and tensile stress component and $F^{\mathrm{Di}}$ represents damage potential function, which meets the following:

$$
F^{D i}=F \exp \left[\frac{a_{1}\left(\sigma_{\mathrm{eq}}^{D i}-a_{10}\right)}{a_{2}}\right]
$$

where $a_{10}$ is the material constant.

Coupling rupture and creep through $F$ function, the following equation can be obtained:

$$
\begin{aligned}
\dot{\varepsilon}_{s}^{D i}= & a_{11}\left[B_{1} \exp \left(-\frac{Q_{1}}{R T}\right)+B_{2} \exp \left(-\frac{Q_{2}}{R T}\right)\right] D_{0} \exp \left(a_{12} D\right) \\
& \cdot\left\{\sinh \left[\frac{a_{3} \sigma_{\mathrm{eq}}^{D i} H\left(\sigma_{\mathrm{eq}}^{D i}\right)}{u(1-D)}\right]\right\}^{n_{3}},
\end{aligned}
$$

where $a_{11}, a_{12}$, and $n_{3}$ are material constants and $D_{0}$ is the initial damage variable.

The equivalent strain rate of healing can be described as follows:

$$
\dot{\varepsilon}_{\mathrm{eq}}^{h}=\frac{\varepsilon_{v}\left(\sigma_{\mathrm{eq}}^{h}-\sigma_{b}\right) H\left(\sigma_{\mathrm{eq}}^{h}-\sigma_{b}\right)}{\tau \mu},
$$

where $\sigma_{\mathrm{eq}}^{h}-\sigma_{b}$ is the process driving force.

In the MDCF model, damage evolution is described in terms of an evolution equation which contains damage growth and healing terms, i.e.,

$$
\dot{\omega}=g\left(\omega, T, \sigma_{\text {eq }}^{d i}, m_{i}\right)-h\left(\omega, T, \sigma_{\text {eq }}^{h}\right),
$$

where $g\left(\omega, T, \sigma_{\text {eq }}^{d i}, m_{i}\right)$ and $h\left(\omega, T, \sigma_{\text {eq }}^{h}\right)$ are used to describe the growth of damage and healing of damage, respectively, and the subscript $i=s$ and $t$ and is corresponding to shear damage and tensile damage, respectively.

The damage growth function $g$ is as follows:

$$
g=\frac{a_{1}}{t_{0}} \omega\left[\ln \left(\frac{1}{\omega}\right)^{\left(a_{1}+1\right) / a_{1}}\right]\left\{\left[\frac{\sigma_{\mathrm{eq}}^{\mathrm{d} s} H\left(\sigma_{\mathrm{eq}}^{\mathrm{d} s}\right)}{m_{s}}\right]^{n_{s}}+\left[\frac{\sigma_{\mathrm{eq}}^{\mathrm{d} t} H\left(\sigma_{\mathrm{eq}}^{\mathrm{d} t}\right)}{m_{t}}\right]^{n_{t}}\right\} \text {. }
$$

The damage healing function $h$ is as follows:

$$
h=\frac{\omega\left(\sigma_{\mathrm{eq}}^{h}-\sigma_{b}\right) H\left(\sigma_{\mathrm{eq}}^{h}-\sigma_{b}\right)}{\tau \mu} .
$$

To illustrate the rationality of the MDCF model, Chan et al. [167-169] carried out larger numbers of triaxial compression creep tests on WIPP (Waste Isolation Pilot Plant) salt rock and Asse salt rock. And the results showed that the predicted results are in good agreement with the experimental results. Meanwhile, the MDCF model is used to analyze the long-term deformation characteristics of WIPP salt rock cavern, which also showed good results. In general, the MDCF model gives a comprehensive description of the microscopic deformation mechanism of salt rock during creep process. However, except for 3 commonly used elastic parameters in the MDCF model, there are still 27 parameters to be determined, and the model form is complicated and inconvenient for application.

3.5.2. Lux/Hou Model. The Lux/Hou model is established by Lux and Hou [170] based on the Lubby2 model, which comprehensively takes the influences of diffusion, dislocation, strain harden, strain recovery, damage, and damage healing mechanisms on the creep behaviors of salt rock into consideration [171]. These mechanisms will affect the development of inelastic strain and strain rate, resulting in the deformation and stress state of salt rock change with the extent of creep time [172].

In the Lux/Hou model, the total strain rate is composed of elastic strain $\dot{\varepsilon}_{i j}^{e}$ and inelastic strain rate $\dot{\varepsilon}_{i j}^{i e}$, i.e.,

$$
\dot{\varepsilon}_{i j}=\dot{\varepsilon}_{i j}^{e}+\dot{\varepsilon}_{i j}^{i e}
$$

Elastic strain rate $\dot{\varepsilon}_{i j}^{e}$ is as follows:

$$
\dot{\varepsilon}_{i j}^{e}=\frac{1}{2 G} \frac{\dot{\delta}_{i j}}{1-D}+\left(\frac{1}{9 K}-\frac{1}{6 G}\right) \frac{L}{1-D} \delta_{i j} .
$$


Inelastic strain rate $\dot{\varepsilon}_{i j}^{i e}$ is as follows:

$$
\dot{\varepsilon}_{i j}^{i e}=\dot{\varepsilon}_{i j}^{v p}+\dot{\varepsilon}_{i j}^{d}+\dot{\varepsilon}_{i j}^{h},
$$

where $\dot{\varepsilon}_{i j}^{v p}$ is the viscoplastic strain rate caused by the mechanisms of diffusion, dislocation, hardening, and recover; $\dot{\varepsilon}_{i j}^{d}$ is the viscoplastic strain rate caused by damage; and $\dot{\varepsilon}_{i j}^{h}$ is the viscoplastic strain rate caused by damage recovery. And $\dot{\varepsilon}_{i j}^{v p}, \dot{\varepsilon}_{i j}^{d}$, and $\dot{\varepsilon}_{i j}^{h}$ respectively, meet the following:

$$
\begin{aligned}
& \dot{\varepsilon}_{i j}^{v p}=\frac{3}{2}\left\{\frac{1}{\bar{\eta}_{K}^{*} \exp \left[k_{2} \sigma_{v} /(1-D)\right]}\left(1-\frac{\varepsilon_{t r}}{\max \left(\varepsilon_{t r}\right)}\right)+\frac{1}{\bar{\eta}_{K}^{*} \exp \left[m \sigma_{v} /(1-D)\right] \exp (l T)}\right\} \frac{S_{i j}}{1-D}, \\
& \dot{\varepsilon}_{i j}^{d}=\dot{\varepsilon}_{i j}^{d s}+\dot{\varepsilon}_{i j}^{d z}=b_{3} \frac{\left\langle F^{\mathrm{d} s} / F^{*}\right\rangle^{b_{1}}}{(1-D)^{b_{2}}} \frac{\partial Q^{\mathrm{d} s}}{\partial \sigma_{i j}}+b_{3} \frac{\left\langle F^{\mathrm{dz}} / F^{*}\right\rangle^{b_{1}}}{(1-D)^{b_{2}}} \frac{\partial Q^{\mathrm{dz}}}{\partial \sigma_{i j}}, \\
& \dot{\varepsilon}_{i j}^{h}=-\frac{\left\langle-\varepsilon_{V o l}\right\rangle}{a_{4}+a_{5} \exp \left(a_{6} \varepsilon_{\mathrm{Vol}}\right)}\left\langle\frac{F^{h}}{F^{*}}\right\rangle \frac{\partial Q_{h}}{\partial \sigma_{i j}}, \quad \varepsilon_{\mathrm{vol}} \leq 0,
\end{aligned}
$$

where $\max \left(\varepsilon_{\mathrm{tr}}\right)$ is the maximum value of initial creep; $F^{\mathrm{ds}}$ and $F^{\mathrm{dz}}$ are, respectively, the damage flow functions caused by shear stress and tensile stress; $Q^{\mathrm{ds}}$ and $Q^{\mathrm{dz}}$ are, respectively, the damage potential functions caused by shear stress and tensile stress; $F^{\mathrm{h}}$ and $Q^{\mathrm{h}}$ are, respectively, the flow function and potential function caused by damage recovery; $D$ is the damage function, and $0 \leq D<1 ; F^{*}=1.0 \mathrm{MPa}$; and $\langle x\rangle$ is the switching function and meets the following:

$$
\langle x\rangle= \begin{cases}0, & x \leq 0, \\ x, & x>0 .\end{cases}
$$

For the flow and potential functions of damage,

$$
\begin{aligned}
F^{\mathrm{d} x} & =\sqrt{3 J_{2}}-\beta_{\text {Dil }}\left(\sigma_{3}, \theta\right)=\sqrt{3 J_{2}}-\eta_{\text {Dil }}\left(\sigma_{3}\right) \beta\left(\sigma_{3}, \theta\right), \\
F^{\mathrm{d} z} & =b_{7}\left[\left\langle-\sigma_{3}\right\rangle+\left\langle-\sigma_{2}\right\rangle+\left\langle-\sigma_{1}\right\rangle-b_{8}\right]^{b_{9}}, \\
Q^{\mathrm{d} s} & =\sqrt{3 J_{2}}-b_{0} F^{s}\left(\sigma_{3}, \theta\right), \\
F^{d z} & =b_{10}\left[\left\langle-\sigma_{3}\right\rangle+\left\langle-\sigma_{2}\right\rangle+\left\langle-\sigma_{1}\right\rangle\right], \\
\beta\left(\sigma_{3}, \theta\right) & =\beta^{\mathrm{TC}}\left(\sigma_{3}, \theta\right) K\left(\sigma_{3}, \theta\right), \\
K\left(\sigma_{3}, \theta\right) & =\left[\frac{1}{\cos (\theta+(\pi / 6))+b_{11} \sin (\theta+(\pi / 6))}\right]^{\exp \left(-b_{12} \sigma_{3}\right)} .
\end{aligned}
$$

For the flow function, potential function, and dynamic equation of damage and damage recovery,

$$
\begin{aligned}
F^{h} & =\frac{2}{3} \sigma_{3}+\frac{2}{3 b_{13}} \ln \left(\frac{b_{14}-\sigma_{v}}{b_{14}}\right), \\
Q^{h} & =\frac{1-b_{15}}{3} \sigma_{1}+\frac{2}{3} \sigma_{3}, \\
D & =S\left(D, F^{\mathrm{d} s}, F^{\mathrm{d} z}, T\right)-h\left(D, F^{h}, \varepsilon_{\mathrm{vol}}, T\right) .
\end{aligned}
$$

For the dynamic equation of damage evolution and damage recovery,

$$
\begin{aligned}
& S=b_{16} \frac{\left[\left\langle F^{\mathrm{d} s} / F^{*}\right\rangle+\left\langle F^{\mathrm{dz}} / F^{*}\right\rangle\right] b_{17}}{(1-D) b_{18}}, \\
& h=\frac{D}{b_{19}+b_{20} \exp \left(b_{21} \varepsilon_{\mathrm{vol}}\right)}\left\langle\frac{F^{h}}{F^{*}}\right\rangle, \quad \varepsilon_{\mathrm{vol}} \leq 0 .
\end{aligned}
$$

In equations (64)-(66), $\beta, \beta^{\mathrm{TC}}$, and $\beta_{\text {Dil }}$ are strength functions; TC is strength and dilatation strength function; $K\left(\sigma_{3}, \theta\right)$ is the modified function considering stress geometrically angular; $\eta_{\text {Dil }}$ is the correlation coefficient of dilatation strength and strength; $S$ and $h$ are growth function of damage and damage recovery; and $b_{0}$ to $b_{21}$ are material constants need to determined.

The Lux/Hou model comprehensively considers the creep, damage, and damage recovery of salt rock, which is more conforming to the actual mechanical characteristics of salt rock USC. At present, the Lux/Hou model has been successfully applied to analyze the creep deformation characteristics of the 4 underground storage caverns in Germany. The lowest operation pressure of gas storage cavern has adjusted from $7 \mathrm{MPa}$ to $4 \mathrm{MPa}$ by using the Lux/ Hou model. And the final lowest operation pressure of this storage cavern is determined as $5 \mathrm{MPa}$ by setting a certain safety coefficient, which acquires better economic performance for energy company [170]. However, the Lux/Hou model involves 31 parameters to be determined, and the accuracy of model parameters directly affects the correctness of the calculation results [172].

\section{Future Perspectives}

Although larger numbers of studies on the creep properties of salt rock and its constitutive model are carried out by scholars in the existing literature, there are still several outstanding problems that need to study in depth, which are closely related to the long-term operation safety and stability 
of the salt rock USC. The opinions and suggestions in future studies on the creep properties and constitutive model of salt rock are listed as follows:

(1) At present, most of the available research studies only take one single factor, such as stress state and temperature, into consideration. However, when the salt rock USC is used to storage radioactive nuclear waste, the decay of radioactive isotopes in nuclear waste will release a lot of heat, which leads to the increasing of surrounding rock temperature. As a result, salt rock is in the coupling effect of temperature and stress, which can further accelerate the development of cracks. At this time, the permeability of salt rock will change that threatens the long-term safety and stability of salt rock USC. Therefore, it is of great important to study the permeability variation of salt rock under the temperature and stress coupling effect during creep process.

(2) The long-term operation process of salt rock USC contains four stages: low-pressure operation, gas injection and pressurization, high-pressure operation, and gas recovery and depressurization. The salt rock will produce creep deformation under constant pressure during the low-pressure operation stage and high-pressure operation stage. During the gas injection and pressurization stage and gas recovery and depressurization stage, the cyclic process of gas injection and recovery is equivalent to imposing a periodic loading on the surrounding rock of salt rock USC. The salt rock will generate fatigue cumulative damage under cyclic loading. At this time, the salt rock is subjected to the effect of creep-fatigue interaction during the long-term operation process of salt rock USC. Therefore, to ensure the safety and stability of salt rock USC, not only the creep and fatigue characteristics of salt rock under constant stress and cyclic loading must be studied but also the damage evolution process under the effect of creepfatigue interaction should be paid attention to.

(3) When the salt rock USC is used to store natural gas, the duration of gas injection and recovery is comparatively long, and the variation of its internal pressure is relatively slow. Namely, the frequency of cyclic loading applied on salt rock is extremely low, whereas the previous research studies mainly focused on the fatigue mechanical properties of salt rock under high frequency (above $1 \mathrm{~Hz}$ ) cyclic loading, which is inconsistent with the actual internal pressure variation (low frequency cyclic loading) of the salt rock USC during the operation process. Therefore, it is necessary to study the deformation characteristics and damage evolution process of salt rock under low frequency cyclic loading.

(4) The obvious nonlinear deformation behavior of salt rock during creep process is closely related to the changes of its internal microstructure. Especially the creep process transits from the decay creep stage to steady creep stage or changes from the steady creep stage to accelerated creep stage, which are inevitably accompanied by the variations of internal microstructure. Therefore, a complete set of theory is required to explain the macroscopic deformation behavior of salt rock during creep process from the microscopic perspective. However, studies on microdeformation mechanisms of salt rock and the relationship between microstructure change and macrocreep behavior during creep process have not been paying sufficient attention, which are need to be strengthened further.

(5) At present, many constitutive models have been proposed by scholars to describe the creep behaviors of salt rock, which are also presenting satisfactory results. However, the macrodeformation behaviors of salt rock are only taken into consideration in most of these models, and the microstructure change in salt rock is ignored during the creep process. Due to excellent capacity of damage self-healing, the damage in salt rock can be healed gradually under proper environment, resulting in the recovery of salt rock mechanical properties to some extent. Therefore, it is an ideal method to establish the creep damage model considering the damage self-healing ability of salt rock based on continuum damage mechanics. At present, the creep models considering the damage self-healing are relatively few, and the form of existing models is complicated and inconvenient for application. Thus, it is necessary to propose a creep constitutive mode of salt rock with simple form, fewer parameters, convenient for application, and considering the damage self-healing ability of salt rock simultaneously.

\section{Conclusions}

In this paper, a comprehensive review on the creep properties of salt rock and its creep constitutive model is presented. The influences of stress state, temperature, and mineral composition on the creep properties of pure or bedded salt rock and its microscopic deformation mechanism are summarised. And the achievements in the creep constitutive model are introduced. Some conclusions are drawn as follows:

(1) The instantaneous strain, creep strain, and steady creep rate of salt rock all increase with axial stress. And the relationship between steady creep rate of salt rock and axial stress can be described by exponential function and power function. There is a critical value for the influence of confining pressure on the creep behavior of salt rock. When confining pressure is lower than the critical value, the creep behavior of salt rock is sensitive to the variation of confining pressure. On the contrary, the creep properties become independent of confining pressure. Moreover, the creep behavior of salt rock is only related the stress state but independent of loading path. 
(2) High temperature can reduce strength and reinforces the ductility of salt rock, resulting in the improvement of creep properties. Therefore, the creep strain and creep rate increase with temperature. Meanwhile, due to the difference in thermal expansion coefficient between different mineral compositions, the mineral particles in salt rock are unable to deform according to their own expansion coefficients. The mineral particles with large deformation are compressed, while the mineral particles with small deformation are stretched. As a result, the thermal stress caused by temperature will be formed at the boundaries of mineral particles, which can able to induce the creep failure of salt rock.

(3) The rheological properties of impurity in salt rock is weaker than that of salt rock grains, and the existence of impurity in salt rock can effectively restrict its overall deformation ability. Therefore, the rheological behavior of salt rock improves obviously with the increasing of $\mathrm{NaCl}$ content. In addition, due to the influence of geological environment, the more microdefects and the more irregular boundaries between grains in salt rock, the more opportunities for salt rock grains to interact with each other and the more easier accumulation at boundaries, which can lead obviously to the strain hardening phenomenon during creep process.

(4) Due to the differences in creep properties between salt rock layer and interlayer, the creep strain of pure salt rock layer and interlayers is uncoordinated that results in the generation of additional stress at the interfaces. Only when the additional stress exceeds the strength of the interface, creep failure of bedded salt rocks happens.

(5) The creep process of salt rock is very complicated, which is mainly governed by dislocation mechanism, diffusion mechanism, and undefined mechanism. The creep process of salt rock may be individually controlled by one mechanism under some specific conditions whereas it is controlled by several mechanisms in parallel in the vast majority of cases. With the continuous development of science and technology, the observation methods of microstructure variation during rock creep process are also becoming increasingly abundant, and SEM and AE technologies are also used to explore the deformation mechanisms of salt rock during creep process.

(6) In terms of the creep constitutive model, the empirical model can describe the creep behavior of salt rock better, but the model parameters are lack of physical meanings. The basic elements in the component combination model and fractional derivatives model are all linear, and whatever how to combine them, the models established still cannot reflect the nonlinear creep behavior of salt rock accurately. Therefore, the creep constitutive models are improved by scholars to overcome this defect, such as establishing nonlinear elements or constructing Abel dashpot based on fractional derivatives theory. The MDCF model and Lux/Hou model comprehensively take the creep, damage, and damage self-healing ability of salt rock into consideration, but the form of these two models is complicated and inconvenient for application.

\section{Data Availability}

The data used to support the findings of this study are available from the corresponding author upon request.

\section{Conflicts of Interest}

The authors declare that they have no conflicts of interest.

\section{Acknowledgments}

This research was funded by the Housing and Urban-Rural Construction Science and Technology Planning Project of Shaanxi Province, under grant number 2019-K39, and the Innovation Capability Support Plan of Shaanxi-Innovation Team, under grant number 2020TD-005.

\section{References}

[1] N. Zhang, L. Ma, M. Wang, Q. Zhang, J. Li, and P. Fan, "Comprehensive risk evaluation of underground energy storage caverns in bedded rock salt," Journal of Loss Prevention in the Process Industries, vol. 45, pp. 264-276, 2017.

[2] M. Yuan, H. R. Zhang, B. H. Wang, L. Q. Huang, K. Fang, and Y. T. Liang, "Downstream oil supply security in China: policy implications from quantifying the impact of oil import disruption," Energy Policy, vol. 136, Article ID 111077, 2020.

[3] G. M. Zhang, L. J. Wang, Y. Wu, Y. P. Li, and S. Y. Yu, "Failure mechanism of bedded salt formations surrounding salt caverns for underground gas storage," Bulletin of Engineering Geology and the Environment, vol. 76, no. 4, pp. 1609-1625, 2016.

[4] M.-M. Xue, G. Wu, Q. Wang, Y.-F. Yao, and Q.-M. Liang, "Socioeconomic impacts of a shortage in imported oil supply: case of China," Natural Hazards, vol. 99, no. 3, pp. 1415-1430, 2019.

[5] T. Wang, J. Li, G. Jing, Q. Zhang, C. Yang, and J. J. K. Daemen, "Determination of the maximum allowable gas pressure for an underground gas storage salt cavern - a case study of Jintan, China," Journal of Rock Mechanics and Geotechnical Engineering, vol. 11, no. 2, pp. 251-262, 2019.

[6] J. Qiu, Z. Guo, L. Yang, H. Jiang, and Y. Zhao, "Effects of packing density and water film thickness on the fluidity behaviour of cemented paste backfill," Powder Technology, vol. 359, pp. 27-35, 2020.

[7] W. Liu, Z. X. Zhang, J. Y. Fan, D. Y. Jiang, Z. Y. Li, and J. Chen, "Research on gas leakage and collapse in the cavern roof of underground natural gas storage in thinly bedded salt rocks," Journal of Energy Storage, vol. 31, Article ID 101669, 2020.

[8] A. Mortazavi and H. Nasab, "Analysis of the behavior of large underground oil storage caverns in salt rock," International Journal for Numerical and Analytical Methods in Geomechanics, vol. 41, no. 4, pp. 602-624, 2017. 
[9] F. Bayram and I. Bektasoglu, "Determination of actual dissolution rates from some rock properties in construction of deep salt cavern for natural gas storage," International Journal of Rock Mechanics and Mining Sciences, vol. 126, Article ID 104183, 2020.

[10] K. Wu, Z. S. Shao, and S. Qin, "Analytical solutions for mechanical response of circular tunnels with double primary linings in squeezing grounds," Geomechanics and Engineering, vol. 22, no. 6, pp. 509-518, 2020.

[11] C.-k. Niu, Y.-f. Tan, J.-n. Li, and C.-l. Song, "Model validation and stability analysis for operation projects in Jintan Salt Cavern for strategic oil storage of China," Journal of Petroleum Science and Engineering, vol. 127, pp. 44-52, 2015.

[12] J. Q. Deng, Y. R. Liu, Q. Yang, W. Cui, Y. B. Zhu, and Y. Liu, "A viscoelastic, viscoplastic, and viscodamage constitutive model of salt rock for underground energy storage cavern," Computer and Geotechnics, vol. 119, Article ID 103288, 2020.

[13] W. Liu, Z. Zhang, J. Chen et al., "Physical simulation of construction and control of two butted-well horizontal cavern energy storage using large molded rock salt specimens," Energy, vol. 185, pp. 682-694, 2019.

[14] X. X. Tian, Z. P. Song, and Y. W. Zhang, "Monitoring and reinforcement of landslide induced by tunnel excavation: a case study from Xiamaixi tunnel," Tunnelling and Underground Space Technology, vol. 110, Article ID 103796, 2021.

[15] R. Tarkowski and G. Czapowski, "Salt domes in Polandpotential sites for hydrogen storage in caverns," International Journal of Hydrogen Energy, vol. 43, no. 46, pp. 21414-21427, 2018.

[16] J. B. Wang, Q. Zhang, Z. P. Song, Y. W. Zhang, and X. R. Liu, "Mechanical properties and damage constitutive model for uniaxial compression of salt rock at different loading rates," International Journal of Damage Mechanics, vol. 30, pp. 1-25, 2021.

[17] H. Mansouri and R. Ajalloeian, "Mechanical behavior of salt rock under uniaxial compression and creep tests," International Journal of Rock Mechanics and Mining Sciences, vol. 110, pp. 19-27, 2018.

[18] W. Han, G. Zhou, D. Gao et al., "Experimental analysis of the pore structure and fractal characteristics of different metamorphic coal based on mercury intrusion-nitrogen adsorption porosimetry," Powder Technology, vol. 362, pp. 386-398, 2020.

[19] U. Yaramanci, "Geoelectric exploration and monitoring in rock salt for the safety assessment of underground waste disposal sites," Journal of Applied Geophysics, vol. 44, no. 2-3, pp. 181-196, 2000.

[20] N. Liu, N. Li, C. Xu, G. Li, Z. Song, and M. Yang, "Mechanism of secondary lining cracking and its simulation for the Dugongling tunnel," Rock Mechanics and Rock Engineering, vol. 53, no. 10, pp. 4539-4558, 2020.

[21] K. Wu, Z. S. Shao, S. Qin, and B. Li, "Determination of deformation mechanism and countermeasures in silty clay tunnel," Journal of Performance of Constructed Facilities, vol. 34, no. 1, Article ID 04019095, 2020.

[22] J. Sun, "Rock rheological mechanics and its advance in engineering applications," Chinese Journal of Rock Mechanics and Engineering, vol. 26, no. 6, pp. 1081-1106, 2007.

[23] J. B. Wang, Q. Zhang, Z. P. Song, and Y. W. Zhang, "Experimental study on creep properties of salt rock under longperiod cyclic loading," International Journal of Fatigue, vol. 143, Article ID 106009, 2021.

[24] Z. F. Chu, Z. J. Wu, Q. S. Liu, and B. G. Liu, "Analytical solutions for deep-buried lined tunnels considering longitudinal discontinuous excavation in rheological rock mass," Journal of Engineering Mechanics, vol. 146, no. 6, Article ID 04020047, 2020.

[25] Y. P. Li, X. S. Chen, X. L. Shi, N. Zhang, C. K. Ma, and C. H. Yang, "Analysis of the plugging process of the leaking interlayer in a thin interbedded salt cavern gas storage of Jintan (China) by high-pressure grouting and potential applications," Journal of Natural Gas Science and Engineering, vol. 68, Article ID 102918, 2019.

[26] W. B. Han, G. Zhou, Q. T. Zhang, H. W. Pan, and D. Liu, "Experimental study on modification of physicochemical characteristics of acidified coal by surfactants and ionic liquids," Fuel, vol. 266, Article ID 116966, 2020.

[27] K. Wu, Z. S. Shao, S. Qin, W. Wei, and Z. Chu, "A critical review on the performance of yielding supports in squeezing tunnels," Tunnelling and Underground Space Technology, vol. 114, Article ID 103815, 2021.

[28] W. Li, C. Zhu, C. Yang, K. Duan, and W. Hu, "Experimental and DEM investigations of temperature effect on pure and interbedded rock salt," Journal of Natural Gas Science and Engineering, vol. 56, pp. 29-41, 2018.

[29] W. Liu, Z. X. Zhang, J. Chen et al., "Feasibility evaluation of large-scale underground hydrogen storage in bedded salt rocks of China: a case study in Jiangsu province," Energy, vol. 198, Article ID 117348, 2020.

[30] B. Hu, S.-q. Yang, and P. Xu, "A nonlinear rheological damage model of hard rock," Journal of Central South University, vol. 25, no. 7, pp. 1665-1677, 2018.

[31] Z. F. Chu, Z. J. Wu, B. G. Liu, and Q. S. Liu, "Coupled analytical solutions for deep-buried circular lined tunnels considering tunnel face advancement and soft rock rheology effects," Tunnelling and Underground Space Technology, vol. 94, Article ID 103111, 2019.

[32] Y. Guo, C. Yang, and H. Mao, "Mechanical properties of Jintan mine rock salt under complex stress paths," International Journal of Rock Mechanics and Mining Sciences, vol. 56, pp. 54-61, 2012.

[33] W. Liu, X. Zhang, J. Y. Fan, J. J. Zuo, Z. X. Zhang, and J. Chen, "Study on the mechanical properties of man-made salt rock samples with impurities," Journal of Natural Gas Science and Engineering, vol. 84, Article ID 103683, 2020.

[34] K. Wu, Z. S. Shao, S. Qin, N. Zhao, and H. Hu, "Analyticalbased assessment of effect of highly deformable elements on tunnel lining within viscoelastic rocks," International Journal of Applied Mechanics, vol. 12, no. 3, Article ID 2050030, 2020.

[35] C. H. Yang, S. W. Bai, and Y. M. Wu, "Stress level and loading path effect on time dependent properties of salt rock," Chinese Journal of Rock Mechanics and Engineering, vol. 19, no. 3, pp. 270-275, 2000.

[36] C. H. Yang, X. P. Gao, and W. Wu, "Experiment studies and theoretic analysis of time dependent properties of rock salt," Journal of Liaoning Technical University, vol. 23, no. 6, pp. 764-766, 2004.

[37] B. P. Xi, Y. S. Zhao, J. C. Zhao, and S. G. Xu, "Study on coupled thermo-mechanical creep properties of bedded rock salt," Chinese Journal of Rock Mechanics and Engineering, vol. 27, no. 1, pp. 90-96, 2008.

[38] S. Rahimi and M. Hosseini, "Laboratory studies of creep behavior on thick-walled hollow cylindrical salt rock specimens," Arabian Journal of Geosciences, vol. 8, no. 8, pp. 5949-5957, 2015.

[39] C. Du, C. H. Yang, H. L. Ma, X. L. Shi, and J. Chen, "Study of creep characteristics of deep rock salt," Rock and Soil Mechanics, vol. 33, no. 8, pp. 2451-2520, 2012. 
[40] J. B. Wang, X. R. Liu, X. Yang, and J. Q. Guo, “Test on creep properties of salt rock under different loading paths," Journal of PLA, vol. 14, no. 5, pp. 517-523, 2013.

[41] C. Wu, J. F. Liu, Z. W. Zhou et al., "Study on creep properties of salt rock with impurities during triaxial creep test," Advanced Engineering Sciences, vol. 49, no. S2, pp. 168-175, 2017.

[42] K. Wu and Z. S. Shao, "Visco-elastic analysis on the effect of flexible layer on mechanical behavior of tunnels," International Journal of Applied Mechanics, vol. 11, no. 3, Article ID 1950027, 2019.

[43] W. B. Han, G. Zhou, M. Y. Xing et al., "Experimental investigation on physicochemical characteristics of coal treated with synthetic sodium salicylate-imidazole ionic liquids," Journal of Molecular Liquids, vol. 318, Article ID 114822, 2021.

[44] B. Hu, M. Sharifzadeh, X. T. Feng, W. B. Guo, and B. Talebi, "Roles of key factors on large anisotropic deformations at deep underground excavations," International Journal of Mining Science and Technology, vol. 114, no. 2, pp. 1-15, 2021.

[45] W. J. Soppe, H. Donker, A. García Celma, and J. Prij, "Radiation-induced stored energy in rock salt," Journal of Nuclear Materials, vol. 217, no. 1-2, pp. 1-31, 1994.

[46] J. Chen, L. Yin, S. Ren, L. Lin, and J. Fang, "The thermal damage properties of mudstone, gypsum and rock salt from Yingcheng, Hubei, China," Minerals, vol. 5, no. 1, pp. 104-116, 2015.

[47] K. Wu, Z. S. Shao, and S. Qin, "An analytical design method for ductile support structures in squeezing tunnels," Archives of Civil and Mechanical Engineering, vol. 20, 91 pages, 2020.

[48] L. P. Paneru, S. J. Bauer, and J. C. Stormont, "Thermal properties of consolidated granular salt as a backfill material," Rock Mechanics and Rock Engineering, vol. 51, no. 3, pp. 911-923, 2018.

[49] U. Hunsche and A. Hampel, "Rock salt-The mechanical properties of the host rock material for a radioactive waste repository," Engineering Geology, vol. 52, no. 3-4, pp. 271-291, 1999.

[50] X. P. Gao, C. H. Yang, and W. Wu, "Experimental studies on time dependent properties of rock salt," Chinese Journal of Geotechnical Engineering, vol. 27, no. 5, pp. 558-561, 2005.

[51] L. Wan, "A visco-elastoplastic damage constitutive model of rock and rock-like materials and applications," Ph.D. thesis, Chongqing University, Chongqing, China, 2004.

[52] P. Li, J. C. Deng, W. Y. Zhao, and Y. C. Feng, "An experimental study on creep characteristics of salt rock and gypsum-salt rock in Puguang gas field," Petroleum Science and Technology, vol. 30, pp. 1715-1724, 2012.

[53] J. W. Chen, C. H. Yang, X. P. Gao, X. H. Li, and D. Y. Jiang, "Study on the coupled damage of temperature and mechanics for salt rock," Chinese Journal of Rock Mechanics and Engineering, vol. 24, no. 11, pp. 1986-1991, 2005.

[54] K. Wu and Z. Shao, "Study on the effect of flexible layer on support structures of tunnel excavated in viscoelastic rocks," Journal of Engineering Mechanics, vol. 145, no. 10, Article ID 04019077, 2019.

[55] H. Zhang, Z. Wang, Y. Zheng, P. Duan, and S. Ding, "Study on tri-axial creep experiment and constitutive relation of different rock salt," Safety Science, vol. 50, no. 4, pp. 801-805, 2012.

[56] Z. Chu, Z. Wu, Q. Liu, B. Liu, and J. Sun, "Analytical solution for lined circular tunnels in deep viscoelastic Burgers rock considering the longitudinal discontinuous excavation and sequential installation of liners," Journal of Engineering Mechanics, vol. 147, no. 4, Article ID 04021009, 2021.

[57] G. Zhang, Y. Wu, L. Wang, K. Zhang, J. J. K. Daemen, and W. Liu, "Time-dependent subsidence prediction model and influence factor analysis for underground gas storages in bedded salt formations," Engineering Geology, vol. 187, pp. 156-169, 2015.

[58] W. Wan, M. Wang, and Y. L. Zhao, "Fluid-solid coupling experimental study on damage bedded rock salt," Journal of Central South University (Science and Technology), vol. 47, no. 7, pp. 2341-2346, 2016.

[59] W. G. Liang, S. G. Xu, Y. S. Zhao, and C. H. Yang, "Experimental study on creep property of rock salt," Chinese Journal of Rock Mechanics and Engineering, vol. 25, no. 7, pp. 1386-1390, 2006.

[60] Y. Ma, M. Chen, C. H. Yang, P. Yang, S. B. Lu, and Y. Jin, "Study of effects of gypsum content on salt-gypsum stratum creep rate," Chinese Journal of Rock Mechanics and Engineering, vol. 32, no. S2, pp. 3238-3244, 2013.

[61] X. D. Qiu, Y. Jiang, Z. L. Yan, and Q. C. Zhuang, "Creep damage failure of rock salt," Journal of Chongqing University, vol. 26, no. 3, pp. 106-109, 2003.

[62] N. N. Malinin and Khadjinsky, "Theory of creep with anisotropic hardening," International Journal of Mechanical Sciences, vol. 14, no. 4, pp. 235-246, 1972.

[63] C. Yang, J. J. K. Daemen, and J.-H. Yin, "Experimental investigation of creep behavior of salt rock," International Journal of Rock Mechanics and Mining Sciences, vol. 36, no. 2, pp. 233-242, 1999.

[64] W. Liu, Y. P. Li, C. H. Yang et al., "A new method of surface subsidence prediction for natural gas storage cavern in bedded rock salts," Environmental Earth Sciences, vol. 75, no. 9, Article ID 800, 2016.

[65] T. Wang, C. Yang, J. Li, J. Li, X. Shi, and H. Ma, "Failure analysis of overhanging blocks in the walls of a gas storage salt cavern: a case study," Rock Mechanics and Rock Engineering, vol. 50, no. 1, pp. 125-137, 2017.

[66] W. Xing, J. Zhao, Z. Hou, P. Were, M. Li, and G. Wang, "Horizontal natural gas caverns in thin-bedded rock salt formations," Environmental Earth Sciences, vol. 73, no. 11, pp. 6973-6985, 2015

[67] L. J. Ma, H. F. Xu, M. Y. Wang, and E. B. Li, "Numerical study of gas storage stability in bedded rock salt during the complete process of operating pressure runaway," Chinese Journal of Rock Mechanics and Engineering, vol. 34, no. S2, pp. 4108-4115, 2015.

[68] Z. W. Zhou, J. F. Liu, F. Wu et al., "Experimental study on creep properties of salt rock and mudstone from bedded salt rock gas storage," Journal of Sichuan University (Engineering Science Edition), vol. 48, no. S1, pp. 100-106, 2016.

[69] M. M. Tang, Z. Y. Wang, G. S. Ding, and Z. N. Ran, "Creep property experiment and constitutive relation of salt-mudstone interlayer," Journal of China Coal Society, vol. 35, no. 1, pp. 42-45, 2010.

[70] A. M. Wang, X. G. Li, C. H. Yang, and Z. Q. Huang, "Study of interaction between creep deformation of bedded salt rock," Rock and Soil Mechanics, vol. 31, no. 12, pp. 3964-3970, 2010.

[71] Y. L. Zhao, Y. Zhang, and W. Wan, "Mechanical properties of bedded rock salt and creep failure model," Mineral Engineering Research, vol. 25, no. 1, pp. 16-20, 2010.

[72] W. G. Liang, C. H. Yang, and Y. S. Zhao, "Physico-mechanical properties and limit operation pressure of gas deposit in bedded salt rock," Chinese Journal of Rock Mechanics and Engineering, vol. 27, no. 1, pp. 22-27, 2008. 
[73] J. W. Ma, Z. Y. Wang, Y. L. Zheng, and Y. J. Zhao, "Creep deformation difference of bedded salt rocks and its additional stress," Acta Petrolei Sinica, vol. 35, no. 1, pp. 178-183, 2014.

[74] G. Wang, K. Guo, M. Christianson, and H. Konietzky, "Deformation characteristics of rock salt with mudstone interbeds surrounding gas and oil storage cavern," International Journal of Rock Mechanics and Mining Sciences, vol. 48, no. 6, pp. 871-877, 2011.

[75] F. Chen, Y. P. Li, C. H. Yang, and C. Zhang, "Experimental study on creep behaviors of rock salt in Yunying salt mine," Chinese Journal of Rock Mechanics and Rock Engineering, vol. 25, no. S1, pp. 3022-3027, 2006.

[76] X. L. Huang, C. H. Yang, and Y. P. Li, "Interface shear stress distribution of bedded salt rock considering rheology effect," Chinese Journal Underground Space Engineering, vol. 10, no. 3, pp. 547-551, 2014.

[77] W. Xing, J. Zhao, U. Düsterloh et al., "Experimental study of mechanical and hydraulic properties of bedded rock salt from the Jintan location," Acta Geotechnica, vol. 9, no. 1, pp. 145-151, 2014.

[78] A. Pouya, "Micro-macro approach for the rock salt behaviour," European Journal of Mechanics-A/Solids, vol. 19, no. 6, pp. 1015-1028, 2000.

[79] J. W. Chen, "Study on temperature effect of mechanical properties and micro mechanism of rock salt," Ph.D. thesis, Wuhan Institute of Rock and Rock Mechanics, Chinese Academy of Science, Wuhan, China, 2008.

[80] M. F. Ashby, "A first report on deformation-mechanism maps," Acta Metallurgica, vol. 20, no. 7, pp. 887-897, 1972.

[81] D. E. Munson and P. R. Dawson, Constitutive Model for the Low Temperature Creep of Salt (With Application to WIPP), SAND79-1853, Sandia National Laboratories, Albuquerque, NM, USA, 1979.

[82] P. A. L. P. Firme, D. Roehl, C. Romanel, and C. Romanel, "An assessment of the creep behaviour of Brazilian salt rocks using the multi-mechanism deformation model," Acta Geotechnica, vol. 11, no. 6, pp. 1445-1463, 2016.

[83] D. E. Munson, K. L. Devries, A. F. Fossum, and G. D. Callahan, "Extension of the M-D model for treating stress drops in salt," in Proceedings of the $3 r$ Conference on the Mechanical Behavior of Salt, H. R. Hardy Jr. and N. larger, Eds., Translation Technique Publication, Palaiseau, France, pp. 31-44, September 1993.

[84] S. T. Horseman and T. J. McEwen, "Thermal constraints on disposal of heat-emitting waste in argillaceous rocks," Engineering Geology, vol. 41, no. 1-4, pp. 5-16, 1996.

[85] N. L. Carter, S. T. Horseman, J. E. Russell, and L. Handin, "Rheology of rocksalt," Journal of Structure Geology, vol. 15, no. 9-10, pp. 1257-1271, 1993.

[86] C. J. Spiers and N. L. Carter, "Microphysics of rocksalt flow in nature," Edited by M. Aubertin and H. R. Hardy, Eds., in Proceedings of the 4th conference the mechanical behavior of salt, Transport Technical Publication, Series on Rock and Soil Mechanics, vol. 22, pp. 115-128, Montreal, Canada, June 1998.

[87] N. Muhammad, C. J. Spiers, C. J. Peach, and H. de Bresser, Effect of Confining Pressure on Plastic Flow of Salt at $125^{\circ} \mathrm{C}$, pp. 57-64, CRC Press, London, UK, 2012.

[88] N. L. Carter and F. D. Hansen, "Creep of rocksalt," Tectonophysics, vol. 92, no. 4, pp. 275-333, 1983.

[89] J. P. Poirier, "High-temperature creep of single crystalline sodium chloride," Philosophical Magazine, vol. 26, no. 3, pp. 701-712, 1972.
[90] G. Desbois, J. L. Urai, P. A. Kukla et al., "Distribution of brine in grain boundaries during static recrystallization in wet, synthetic halite: insight from broad ion beam sectioning and SEM observation at cryogenic temperature," Contributions to Mineralogy and Petrology, vol. 163, no. 1, pp. 19-31, 2012.

[91] C. L. Hwang, M. L. Wang, and S. Miao, "Proposed healing and consolidation mechanisms of rock salt revealed by ESEM," Microscopy Research and Technique, vol. 25, no. 5-6, pp. 456-464, 1993.

[92] O. Schenk, J. L. Urai, and S. Piazolo, "Structure of grain boundaries in wet, synthetic polycrystalline, statically recrystallizing halite - evidence from cryo-SEM observations," Geofluids, vol. 6, no. 1, pp. 93-104, 2006.

[93] G. Desbois, J. L. Urai, and J. H. P. de Bresser, "Fluid distribution in grain boundaries of natural fine-grained rock salt deformed at low differential stress (Qom Kuh salt fountain, central Iran): implications for rheology and transport properties," Journal of Structural Geology, vol. 43, pp. 128-143, 2012.

[94] J. Y. Ding, H. W. Zhou, and J. X. Zhang, "Contrast study on micromechanisms of dry and wet synthetic rocksalt rheology," Journal of Xi'an University of Science and Technology, vol. 37, no. 4, pp. 455-460, 2017.

[95] D. S. Yang, W. Z. Chen, J. P. Yang, and G. J. Wu, “Application of digital image correlation technique in experimental study of the creep behavior and time dependent damage of natural rock salt," Journal of Testing Evaluation, vol. 42, no. 2, pp. 220-226, 2012.

[96] Y. L. Yang, W. G. Liang, X. Q. Yang, M. T. Cao, J. Li, and N. Xiao, "Temperature effect on creep of glauberite salt rock under multi-field coupling," Journal of China Coal Society, vol. 45, no. 3, pp. 1070-1080, 2020.

[97] Y. Filimonov, A. Lavrov, and V. Shkuratnik, "Acoustic emission in rock salt: effect of loading rate," Strain, vol. 38, no. 4, pp. 157-159, 2002.

[98] C. Zhang, W. Liang, Z. Li, S. Xu, and Y. Zhao, “Observations of acoustic emission of three salt rocks under uniaxial compression," International Journal of Rock Mechanics and Mining Sciences, vol. 77, pp. 19-26, 2015.

[99] V. L. Shkuratnik and E. A. Novikov, "Influence of the mechanical loading of rock salt on the parameters of thermoacoustic emission," Journal of Applied Mechanics and Technical Physics, vol. 56, no. 3, pp. 486-493, 2015.

[100] C. Wu, J. F. Liu, Z. W. Zhou, and Z. Zhuo, "Creep acoustic emission of rock salt under triaxial compression," Chinese Journal of Geotechnical Engineering, vol. 38, no. S2, pp. 318-323, 2016.

[101] Y. Zeng, J. F. Liu, Z. W. Zhou, C. Wu, and Z. C. Li, "Creep acoustic emission and damage evolution of salt rock under uniaxial compression," Rock and Soil Mechanics, vol. 40, no. 1, pp. 207-215, 2019.

[102] H. W. Zhou, C. P. Wang, L. Mishnaevsky, Z. Q. Duan, and J. Y. Ding, "A fractional derivative approach to full creep regions in salt rock," Mechanics of Time-dependent Materials, vol. 17, no. 3, pp. 412-425, 2013.

[103] J. B. Wang, X. R. Liu, M. Huang, and X. J. Liu, "A nonstationary viscoelasto-plastic creep model for salt rock," Disaster Advances, vol. 6, pp. 9-101, 2013.

[104] N. D. Cristescu, "A general constitutive equation for transient and stationary creep of rock salt," International Journal of Rock Mechanics and Mining Sciences \& Geomechanics Abstracts, vol. 30, no. 2, pp. 125-140, 1993. 
[105] J. Jin and N. D. Cristescu, "An elastic/viscoplastic model for transient creep of rock salt," International Journal of Plasticity, vol. 14, no. 1-3, pp. 85-107, 1998.

[106] B. P. Xi, S. G. Xu, Y. L. Zhao, and Y. S. Zhao, "Experimental study and theoretic analysis on creep property of rock salt interlayer," Journal of Taiyuan University of Technology, vol. 37, no. 2, pp. 123-126, 2006.

[107] H. Özşena, İ. Özkana, and C. Şensöğütb, "Measurement and mathematical modelling of the creep behaviour of Tuzköy rock salt," International Journal of Rock Mechanics and Mining Sciences, vol. 66, pp. 128-135, 2014.

[108] F. D. Hansen, Case History Rock Mechanics Examination of the Jefferson Island Salt Mine: II. Laboratory Evaluation of Strength and Creep Deformation Characteristics of Dome Salt under Confining Pressure, Office of Waste Isolation, Rapid City, SD, USA, 1977.

[109] D. Griggs, "Creep of rocks," The Journal of Geology, vol. 47, no. 3, pp. 225-251, 1939.

[110] Z. Hou, "Mechanical and hydraulic behavior of rock salt in the excavation disturbed zone around underground facilities," International Journal of Rock Mechanics and Mining Sciences, vol. 40, no. 5, pp. 725-738, 2003.

[111] W. G. Cao, K. Chen, X. Tan, and H. Chen, "A novel damagebased creep model considering the complete creep process and multiple stress levels," Computer and Geotechnics, vol. 124, Article ID 103599, 2020.

[112] R. Wang, Y. Jiang, C. Yang, F. Huang, and Y. Wang, "A nonlinear creep damage model of layered rock under unloading condition," Mathematical Problems in Engineering, vol. 2018, pp. 1-8, Article ID 8294390, 2018.

[113] A. Singh, C. Kumar, L. G. Kannan, K. S. Rao, and R. Ayothiraman, "Estimation of creep parameters of rock salt from uniaxial compression tests," International Journal of Rock Mechanics and Mining Sciences, vol. 107, pp. 243-248, 2018.

[114] J. B. Wang, X. R. Liu, M. Huang, and X. Yang, "Analysis of axial creep properties of salt rock under low frequency cyclic loading using Burgers model," Rock and Soil Mechanics, vol. 35, no. 4, pp. 933-942, 2014.

[115] S. G. Xu, W. G. Liang, B. P. Xi, and Y. L. Zhao, "Study on creep property of glauberite salt rock," Chinese Journal of Rock Mechanics and Engineering, vol. 27, no. S2, pp. 35163520, 2008.

[116] W. G. Liang, M. T. Cao, X. Q. Yang, C. D. Zhang, and S. G. Xu, "Experimental study on creep of glauberite salt rock under coupled compression and dissolution," Chinese Journal of Rock Mechanics and Engineering, vol. 35, no. 12, pp. 2461-2470, 2016.

[117] J. Liu, C. H. Yang, W. Wu, and X. P. Gao, "Study on creep characteristics and constitutive relation of rock salt," Rock and Soil Mechanics, vol. 27, no. 8, pp. 1267-1271, 2006.

[118] B. P. Xi, Y. S. Zhao, Y. L. Zhao, and S. G. Xu, "Study on creep property of rock salt with mudstone interlayer," Chinese Journal Underground Space Engineering, vol. 3, no. 1, pp. 23-26, 2007.

[119] Z. R. Wang, L. M. Zhang, and Z. Y. Han, "A study of the creep properties and the test model of the inter bedded salt rock in the Pingdingshan salt field," Hydrogeology and Engineering Geology, vol. 41, no. 5, pp. 125-137, 2014.

[120] J. B. Wang, X. R. Liu, Z. P. Song, B. Y. Zhao, N. Jiang, and T. Z. Huang, "A whole process creeping model of salt rock under uniaxial compression based on inverse S function," Chinese Journal of Rock Mechanics and Engineering, vol. 37, no. 11, pp. 2446-2459, 2018.
[121] J. Wang, Q. Zhang, Z. Song, and Y. Zhang, “Creep properties and damage constitutive model of salt rock under uniaxial compression," International Journal of Damage Mechanics, vol. 29, no. 6, pp. 902-922, 2020.

[122] W. L. Chen, F. S. Zhao, and H. J. Gong, "Study of creep parameters of mica-quartzose schist during triaxial creep test," Chinese Journal of Rock Mechanics and Engineering, vol. 30, no. S1, pp. 2810-2816, 2011.

[123] C. Ping, Y. D. Wen, Y. X. Wang, H. P. Yuan, and B. X. Yuan, "Study on nonlinear damage creep constitutive model for high-stress soft rock," Environmental Earth Sciences, vol. 75, no. 10, Article ID 900, 2016.

[124] F. Wu, R. B. Gao, J. Liu, and C. B. Li, "New fractional variable-order creep model with short memory," Applied Mathematics and Computer, vol. 380, Article ID 125278, 2020.

[125] H. J. Chen, W. Y. Xu, W. Wang, R. B. Wang, and C. Shi, “A nonlinear viscoelastic-plastic rheological model for rocks based on fractional derivative theory," International Journal of Modern Physics B, vol. 27, no. 25, Article ID 1350149, 2013.

[126] G. Peng, Z. Q. Chen, and J. R. Chen, "Research on rock creep characteristics based on the fractional calculus meshless method," Advances in Civil Engineering, vol. 2018, Article ID 1472840, 6 pages, 2018.

[127] S. G. Zhang and W. B. Liu, "The 3D Nonstationary creep constitutive model of sandstone based on fractional order," Mathematical Problems in Engineering, vol. 2019, Article ID 6031842, 12 pages, 2019.

[128] S. Kempfle, I. Schäfer, and H. Beyer, "Fractional calculus via functional calculus: theory and applications," Nonlinear Dynamics, vol. 29, no. 1, pp. 99-127, 2002.

[129] V. Kiryakova and B. Al-Saqabi, "Explicit solutions to hyperBessel integral equations of second kind," Computers \& Mathematics with Applications, vol. 37, no. 1, pp. 75-86, 1999.

[130] H. W. Zhou, C. P. Wang, B. B. Han, and Z. Q. Duan, “A creep constitutive model for salt rock based on fractional derivatives," International Journal of Rock Mechanics and Mining Sciences, vol. 48, no. 1, pp. 116-121, 2011.

[131] S. Y. Pu, Z. D. Zhu, L. Song, W. L. Song, and Y. Y. Peng, "Fractional-order visco-elastoplastic constitutive model for rock under cyclic loading," Arabian Journal of Geoscience, vol. 13, no. 9, Article ID 326, 2020.

[132] H. Tang, D. Wang, R. Huang, X. Pei, and W. Chen, "A new rock creep model based on variable-order fractional derivatives and continuum damage mechanics," Bulletin of Engineering Geology and the Environment, vol. 77, no. 1, pp. 375-383, 2018.

[133] J. Chen, D. Lu, F. Wu, J. Fan, and W. Liu, “A non-linear creep constitutive model for salt rock based on fractional derivatives," Thermal Science, vol. 23, no. S3, pp. 773-779, 2019.

[134] H. Tang, D. P. Wang, and Z. Duan, "New Maxwell creep model based on fractional and elastic-plastic elements," Advances in Civil Engineering, vol. 2020, Article ID 9170706, 11 pages, 2020.

[135] H. W. Zhou, D. Liu, G. Lei, and Y. Zhao, “The creep-damage model of salt rock based on fractional derivative," Energies, vol. 11, no. 9, Article ID 2349, 2018.

[136] Y. W. Wang, W. Wang, Q. Y. Zhou, and S. Y. Mei, "Study on rock creep model based on unsteady fractional order calculus theory," Journal of Hebei University Engineering (Natural Science Edition), vol. 36, no. 2, pp. 60-69, 2019.

[137] F. Wu, J. F. Liu, and J. Wang, "An improved Maxwell creep model for rock based on variable-order fractional 
derivatives," Environmental Earth Sciences, vol. 73, no. 11, pp. 6965-6971, 2015.

[138] H. Zhou, C. Wang, J. Liu, M. Zhang, and Z. Duan, “基于分 数阶导数的盐岩流变本构模型,”Scientia Sinica Physica, Mechanica \& Astronomica, vol. 42, no. 3, pp. 310-318, 2012.

[139] J. Y. Ding, H. W. Zhou, C. Li, C. P. Wang, and Z. W. Wu, "The fractional derivative approach to creep constitutive model of salt rock based on Weibull distribution," Chinese Journal of Solid Mechanics, vol. 34, no. 5, pp. 473-480, 2013.

[140] D. Liu, H. W. Zhou, Y. Zhao, X. Duan, and J. Y. Ding, "Study of creep constitutive model of rock salt based on acoustic emission characteristics," Rock and Soil Mechanics, vol. 38, no. 7, pp. 1951-1958, 2017.

[141] F. Wu, H. P. Xie, J. F. Liu, Y. Bian, and J. L. Pei, "Experimental study of fractional viscoelastic-plastic creep model," Chinese Journal of Rock Mechanics and Engineering, vol. 33, no. 5, pp. 964-970, 2014.

[142] B. Krishnan, S. V. Jitendra, and V. P. Raghu, "Creep damage characterization using a low amplitude nonlinear ultrasonic technique," Materials Characterization, vol. 62, no. 3, pp. 275-286, 2011.

[143] J. Y. Ding, H. W. Zhou, D. Liu, Q. Chen, and J. F. Liu, "Research on fractional derivative three elements model of salt rock," Chinese Journal of Rock Mechanics and Engineering, vol. 33, no. 4, pp. 672-678, 2014.

[144] L.-J. Ma, X.-Y. Liu, Q. Fang et al., "A new elasto-viscoplastic damage model combined with the generalized Hoek-Brown failure criterion for bedded rock salt and its application," Rock Mechanics and Rock Engineering, vol. 46, no. 1, pp. 53-66, 2013.

[145] S.-Q. Yang and L. Cheng, "Non-stationary and nonlinear visco-elastic shear creep model for shale," International Journal of Rock Mechanics and Mining Sciences, vol. 48, no. 6, pp. 1011-1020, 2011.

[146] X. Q. Lv, “The creep calculation method of variable parameters on rock mass engineering," Journal of Wuhan University of Technology, vol. 2, pp. 201-207, 1987.

[147] J. B. Wang, X. R. Liu, J. Q. Guo, and M. Huang, "Creep properties of salt rock and its nonlinear constitutive model," Journal of China Coal Society, vol. 39, no. 3, pp. 445-451, 2014.

[148] X. Liu, X. Yang, and J. Wang, "A nonlinear creep model of rock salt and its numerical implement in FLAC3D," Advances in Materials Science and Engineering, vol. 2015, pp. 1-8, 2015.

[149] J. B. Wang, X. R. Liu, Z. S. Shao, and T. H. Wang, "A study of the nonlinear creep damage model for rocks," Modern Tunnelling Technology, vol. 51, no. 3, pp. 79-84, 2014.

[150] J. B. Wang, X. R. Liu, Z. P. Song, and Z. S. Shao, "An improved Maxwell creep model for salt rock," Geomechanics and Engineering, vol. 9, no. 4, pp. 499-511, 2015.

[151] L. X. Xiong, D. L. Yang, and Y. Zhang, "Non-stationary Burgers model for rock," Journal of Central South University (Science and Technology), vol. 41, no. 2, pp. 679-684, 2010.

[152] Y. G. Kang and X. E. Zhang, "A non-stationary model for rock creep based on Burgers model," Rock and Soil Mechanics, vol. 40, no. 1, pp. 55-69, 2019.

[153] Y. Han, Y. H. Tan, E. B. Li, J. L. Duan, and S. K. Pu, "Nonstationary Burgers creep model of rock and its parameter identification," Engineering Mechanics, vol. 35, no. 3, pp. 210-217, 2018.

[154] F. He, L. G. Wang, Y. J. Yu, and M. S. Feng, "Non-linear creep model of rock and parameter determination," Journal of Liaoning Technical University,vol. 24, no. 2, pp. 181-183, 2005.

[155] X. J. Liu, X. R. Liu, J. B. Wang, and J. Xu, "Study on nonstationary Kelvin model of low-grade metamorphic slate," Chinese Journal Underground Space Engineering, vol. 11, no. 4, pp. 975-979, 2015.

[156] Q. Z. Hu, X. T. Feng, and H. Zhou, "Study of creep model of rock salt with thermal damage considered," Rock and Soil Mechanics, vol. 30, no. 8, pp. 2245-2248, 2009.

[157] G. Wang, L. Zhang, Y. Zhang, and G. Ding, "Experimental investigations of the creep-damage-rupture behaviour of rock salt," International Journal of Rock Mechanics and Mining Sciences, vol. 66, pp. 181-187, 2014.

[158] W. Z. Chen, Z. C. Wang, G. J. Wu, J. P. Yang, and B. P. Zhang, "Nonlinear creep damage constitutive model of rock salt and its application to engineering," Chinese Journal of Rock Mechanics and Engineering, vol. 26, no. 3, pp. 467472, 2007.

[159] L. Ma, M. Wang, N. Zhang, P. Fan, and J. Li, "A variableparameter creep damage model incorporating the effects of loading frequency for rock salt and its application in a bedded storage cavern," Rock Mechanics and Rock Engineering, vol. 50, no. 9, pp. 2495-2509, 2017.

[160] G. J. Wang, "A constitutive creep-damage model for saline rocks," Rock and Soil Mechanics, vol. 24, no. S2, pp. 81-84, 2003.

[161] G. J. Wang, S. X. Cai, X. Y. Liu, D. Li, and L. Zhang, “A constitutive model coupling creep, damage and healing of salt rock," Journal of Taiyuan University of Technology, vol. 49, no. 3, pp. 423-427, 2018.

[162] F. Chen, C. H. Yang, and S. H. Bai, "Investigation on creep damage of natural gas storage in salt rock layer," Rock and Soil Mechanics, vol. 27, no. 6, pp. 945-949, 2006.

[163] L. J. Ma, X. Y. Liu, Q. Fang, H. M. Xia, and Q. S. Li, “An elasto-viscoplastic damage model combined with generalized Hoek-Brown failure criterion for rock salt and its engineering application," Journal of China Coal Society, vol. 37, no. 8, pp. 1299-1303, 2012.

[164] H. Yin, C. Yang, H. Ma et al., "Study on damage and repair mechanical characteristics of rock salt under uniaxial compression," Rock Mechanics and Rock Engineering, vol. 52, no. 3, pp. 659-671, 2019.

[165] Y. F. Kang, J. Chen, D. Y. Jiang, W. Liu, and J. Y. Fan, "Summary on damage self-healing property of rock salt," Rock and Soil Mechanics, vol. 40, no. 1, pp. 55-69, 2019.

[166] K. S. Chan, S. R. Bodner, A. F. Fossum, and D. E. Munson, "A constitutive model for inelastic flow and damage evolution in solids under triaxial compression," Mechanics of Materials, vol. 14, no. 1, pp. 1-14, 1992.

[167] K. S. Chan, S. R. Bodner, A. F. Fossum, and D. E. Munson, "A damage mechanics treatment of creep failure in rock salt," International Journal of Damage Mechanics, vol. 6, no. 1, pp. 121-152, 1997.

[168] K. S. Chan, S. R. Bodner, and D. E. Munson, "Application of isochronous healing curves in predicting damage evolution in a salt structure," International Journal of Damage Mechanics, vol. 9, no. 2, pp. 130-153, 2000.

[169] K. S. Chan, S. R. Bodner, and D. E. Munson, "Permeability of Wipp salt during damage evolution and healing," International Journal of Damage Mechanics, vol. 10, no. 3, pp. 347-375, 2001.

[170] K. H. Lux and Z. M. Hou, "New developments in mechanical safety analysis of repositories in rock salt," in Proceeding of 
International Conference on Radioactive Waste Disposal, pp. 281-286, Spring Verlag, Cordoba, Spain, March 2000.

[171] Z. M. Hou, "Investigations to prove the stability for underground storage in the salt marshes," Ph.D. thesis, Clausthal University, Clausthal-Zellerfeld, Germany, 1997.

[172] W. Wu, CH. Yang, and Z. M. Hou, "Investigations on studied situations associated with mechanical aspects and development for underground storage of petroleum and natural gas in rock salt," Chinese Journal of Rock Mechanics and Engineering, vol. 24, no. S2, pp. 5561-5568, 2005. 